\title{
Hellenic consensus on Helicobacter pylori infection
}

\section{Sotirios D. Georgopoulos ${ }^{a *}$, Spyridon Michopoulos ${ }^{b *}$, Theodoros Rokkas ${ }^{c *}$, Pericles Apostolopoulos , Evangelos Giamarellos', Dimitrios Kamberoglou', Andreas Mentis', Konstantinos Triantafyllou'}

Athens Medical, P. Faliron Hospital; Alexandra General Hospital; Errikos Dynan Hospital; NIMTS Hospital; Attikon University Hospital; Laiko General Hospital; Hellenic Pasteur Institute, Athens, Greece

${ }^{*}$ These authors contributed equally to the preparation of manuscript.

Abstract

The Hellenic Society of Gastroenterology recently organized the "Hellenic consensus on Helicobacter pylori (H. pylori) infection". The aim of this publication is to report the guidelines in order to aid the national gastroenterology community in the management of $H$. pylori infection. Forty-one delegates from all Greek regions, including gastroenterologists, pathologists, clinical microbiologists, epidemiologists and basic scientists, were invited to this meeting. The participants were allocated to 1 of the 4 main topics of the meeting: i.e., $H$. pylori diagnosis and association with diseases; $H$. pylori and gastric cancer; $H$. pylori and extragastric associated disorders; and $\mathrm{H}$. pylori treatment. The results of each subgroup were submitted to a final consensus vote that included all participants. Relevant data based on international and Greek publications were presented, and the quality of evidence, strength of recommendation, and level of consensus were graded. The cutoff level of $70 \%$ was considered as acceptance for the final statement. It is hoped that the recommendations and conclusions of this report will guide Greek doctors in their daily practice concerning the management of $H$. pylori infection.

Keywords Helicobacter pylori, diagnosis, extragastric associations, treatment, gastric cancer, consensus, Hellenic Society of Gastroenterology

Ann Gastroenterol 2020; 33 (2): 1-21

${ }^{\mathrm{a}}$ Gastroenterology Department, Athens Medical, P. Faliron Hospital (Sotirios D. Georgopoulos); ' Gastroenterology Department Alexandra General Hospital (Spyridon Michopoulos); 'Gastroenterology Department, Errikos Dynan Hospital (Theodoros Rokkas); ${ }^{\mathrm{d}}$ Gastroenterology Department, NIMTS Hospital (Pericles Apostolopoulos); ${ }^{\text {e }} \mathrm{th}^{\text {th }}$ Department of Internal Medicine, Attikon University Hospital (Evangelos Giamarellos); ${ }^{\mathrm{f}} \mathrm{Gastroenterology}$ Department, Laiko General Hospital, (Dimitrios Kamberoglou); 'Laboratory of Medical Microbiology, Hellenic Pasteur Institute, (Andreas Mentis); hastroenterology Department, Attikon University Hospital (Konstantinos Triantafyllou), Athens, Greece

Conflict of Interest: None

Funding: The Hellenic Consensus Conference on Helicobacter pylori infection was funded by the Hellenic Society of Gastroenterology; technical assistance for manuscript preparation was funded by the Hellenic Society for the Study of Helicobacter pylori and Other GI Infections

Correspondence to: Sotirios D. Georgopoulos, MD, FEBGH, AGAF, Director, GI Dept. Athens Medical, P. Faliron Hospital, 144 Kountouriotou Str., 18535 Piraeus, Greece, e-mail: georgpap@ath.forthnet.gr

Received 21 June 2019; accepted 30 October 2019; published online 7 January 2020

DOI: https://doi.org/10.20524/aog.2020.0446

\section{Introduction}

Since its isolation in 1983, Helicobacter pylori (H. pylori) infection has been one of the most interesting research fields in gastroenterology. Its significance in both benign and malignant gastric disease is well recognized all over the world [1], as are its extragastric manifestations [2]. However, its epidemiology varies in various parts of the globe, while in addition research is evolving. As a result, various scientific boards have organized consensus meetings of experts and published the relevant guidelines [2-4]. No doubt these guidelines are very useful and help the clinicians in their clinical practice. However, given the local differences, it is of importance for national scientific gastroenterological societies to organize their own consensus meetings and to adapt guidelines to their own countries [5]. Towards this end, the Hellenic Society of Gastroenterology recently organized the "Hellenic consensus on H. pylori infection". The aim of this publication is to report the guidelines in order to aid the local gastroenterology community in the management of $H$. pylori infection.

\section{Methodology}

Forty-one delegates from all Hellenic regions took part in the conference, including gastroenterologists, pathologists, 
epidemiologists, clinical microbiologists, and basic scientists. Participants were invited for their knowledge and contribution to $H$. pylori infection research. The participants were divided into 4 groups according to their main area of interest/expertise: i.e., H. pylori diagnosis, indications for testing, and disease associations; H. pylori-associated extragastric disorders; H. pylori treatment; and $H$. pylori and gastric malignancy. A coordinator was assigned to each group. Prior to the Consensus conference date, the 3 main coordinators (SDG, SM and TR) held a meeting in Athens at which a questionnaire was drawn up with specific questions for each participant to answer at the consensus meeting, after which these participants were allocated into the 4 groups. Each participant had to make a 10 -min presentation of the topic, citing the relevant references, and then provide a relevant statement, with the strength of recommendations and levels of evidence according to a suitable table on classification of evidence [3] (Table 1). Each presentation was followed by extensive discussion, with modifications, additions and deletions. The conclusions and recommendations from each group were prepared and edited, then presented to all participants for final voting. Each topic was adopted as consensus if at least $70 \%$ of all participants agreed upon it. The questions, together with the relevant statements, the strength of recommendations and levels of evidence, as well as the agreement levels from these proceedings are reported in this paper.

\section{A. Indications/associations/diagnosis}

H. pylori is a human pathogen that causes chronic atrophic gastritis (AG), duodenal ulcer gastric ulcer and gastric mucosaassociated lymphoid tissue (MALT) lymphoma, and is related to the development of gastric cancer. Its eradication can resolve gastritis and may substantially reduce the incidence of the above-mentioned diseases.

Statement 1: A "test-and-treat" strategy should be the first choice for young patients ( $<45$ years old) presenting with uninvestigated dyspepsia. This approach should not be applied to older patients and patients with alarm symptoms.

Recommendation grade: A; Evidence level: 1a; Agreement level: $100 \%$

The "test-and-treat" strategy involves the use of noninvasive tests to detect the presence of $H$. pylori in patients with dyspeptic symptoms, followed by treatment in cases where H. pylori is detected. In countries where the prevalence of H. pylori is higher than $20 \%$, the "test-and-treat" strategy has been recommended for the initial management of patients with uninvestigated dyspepsia to reduce cost, inconvenience and discomfort for the patients [3]. In Greece, as in other European countries, the prevalence of $H$. pylori in adults is more than $20 \%$ [6]. The "test-and-treat" strategy remains the best choice for the general young population, mainly because of economic considerations $[7,8]$. Since the cost of endoscopy in Greece is much lower than in most occidental countries, the increased cost drawback may not be applicable in Greece, although there are no data to support an alternative policy.

Statement 2: Patients with dyspeptic symptoms older than 45 years of age or with alarm symptoms at any age should be referred for upper endoscopy.

Recommendation grade: A; Evidence level: 1a; Agreement level: $100 \%$

Unequivocally, endoscopy is mandatory in patients with alarm symptoms, such as dysphagia, weight loss, iron deficiency anemia, gastrointestinal bleeding or abdominal mass, as well as in older patients where the risk of cancer is higher; in these cases the "test-and-treat" strategy is not appropriate [3]. The panel members unanimously accepted the age-limit of 45 years, in accordance with most international guidelines. In addition, if $H$. pylori prevalence decreases to a level $<20 \%$ in the population under 45 years the "test-and-treat" strategy for uninvestigated dyspepsia should be reevaluated. Consequently, the prevalence of $H$. pylori must be continuously monitored in Greece.

Statement 3: $H$. pylori eradication leads to resolution of functional dyspepsia symptoms in a small number of patients.

Recommendation grade: A; Evidence level: 1a; Agreement level: $\mathbf{9 4 . 4 \%}$

Gastritis caused by $H$. pylori is a distinct entity, and patients with this type of gastritis could have dyspeptic symptoms [9-11]. The Rome IV consensus [12] suggested that, in a subgroup of patients with functional dyspepsia, dyspeptic symptoms can be attributed to $H$. pylori gastritis, termed $H$. pylori-associated dyspepsia, if successful eradication therapy is followed by sustained symptom remission [11]. There is evidence that $H$. pylori eradication in patients with functional dyspepsia is associated with a small but statistically significant benefit in terms of symptom control, compared to no eradication $[13,14]$. It is estimated that this therapeutic strategy leads to a number needed-to-treat between 8 and 14 for symptom resolution $[14,15]$.

Statement 4: $H$. pylori eradication reduces the risk of complicated and uncomplicated gastroduodenal ulcers in non-steroidal anti-inflammatory drug (NSAID)- and aspirin-naïve users. H. pylori eradication is more beneficial if applied before starting NSAID or aspirin treatment, but less in chronic users.

Recommendation grade: A; Evidence level: $1 \mathbf{b}$; Agreement level: $\mathbf{9 5 \%}$ 
NSAIDs, aspirin and H. pylori infection are independent risk factors for peptic ulcer and peptic ulcer complications $[3,16,17]$. A meta-analysis that included data from 25 studies demonstrated that peptic ulcer disease was significantly more common in patients taking NSAIDs who were also infected with $H$. pylori, compared to those without $H$. pylori infection [18]. H. pylori infection and NSAID use increased the relative risk of ulcer bleeding 1.79-fold and 4.85-fold, respectively. When both factors were present, the risk increased to 6.13 [18]. In a Greek study and a meta-analysis, H. pylori infection was found to almost double the risk of bleeding in NSAID users and was the only significant risk factor for upper gastrointestinal bleeding in the multivariate analysis [19]. Naïve NSAID users benefit more than chronic users from $H$. pylori testing and, if positive, treatment, prior to the initiation of NSAIDs [20,21]. Two meta-analyses showed that $H$. pylori eradication is significantly effective for preventing peptic ulcer disease in naïve NSAID users, but that it was less effective in chronic users [22,23]. $H$. pylori eradication has also been shown to reduce peptic ulcer bleeding in aspirin users, although the magnitude of the effect has recently been challenged $[16,24]$. Since $H$. pylori infection is an independent risk factor for peptic ulcer bleeding in patients taking aspirin or other anticoagulants, it seems reasonable to suggest a similar strategy of $H$. pylori eradication for naïve aspirin users as for those taking NSAIDs [25].

Statement 5: H. pylori eradication is highly advisable in NSAID or aspirin users with a history of peptic ulcer disease and upper gastrointestinal bleeding.

Recommendation grade: $\boldsymbol{B}$; Evidence level: $2 \boldsymbol{b}$; Agreement level: $\mathbf{1 0 0 \%}$

In a randomized trial, it was shown that $H$. pylori eradication significantly reduces the rates of ulcer re-bleeding in users of aspirin or, to a lesser degree, NSAIDs who have a history of upper gastrointestinal bleeding, as opposed to therapy with proton pump inhibitors (PPIs) alone [26]. Eradication of $H$. pylori was equivalent to maintenance treatment with PPIs in preventing recurrent bleeding in those taking low-dose aspirin, while PPIs were superior in those taking other NSAIDs [26]. H. pylori eradication reduced but did not eliminate the risk of recurrent bleeding in highrisk patients taking low-dose aspirin [27,28]. Therefore, in NSAID or aspirin users, after an episode of complicated or uncomplicated peptic ulcer, prophylactic therapy with PPI is mandatory in addition to $H$. pylori eradication. This strategy has also been shown to be the most cost-effective, according to a mathematical model [29].

Statement 6: Eradication of $H$. pylori is recommended in patients commencing long-term PPI therapy.

Recommendation grade: A; Evidence level: 1c; Agreement level: $\mathbf{9 5 \%}$
PPI maintenance therapy for 6 months or longer is recommended in certain diseases, such as gastroesophageal reflux disease and Zollinger-Ellison syndrome. Development of gastric pre-malignant lesions in $H$. pylori-infected, long-term PPI users is not universally accepted [30,31]. A meta-analysis of 7 randomized controlled trials (RCTs; 1789 pts), with a high or unclear risk of bias, revealed no clear evidence of corpus gastric atrophy or intestinal metaplasia (IM) progression in long-term (>6 months) PPI users [30]. Although studies in H. pylori-infected Mongolian gerbils showed that PPI treatment accelerated the progression to gastric cancer [32], this has not been confirmed in humans [3]. A meta-analysis of 12 studies (2658 pts) revealed that the eradication of $H$. pylori resulted in a significant improvement in atrophy in the corpus, irrespective of the continuation of acid-suppressive drugs, but no regression of IM [33]. In a systematic review of a total of 16 studies (1920 pts), H. pylori-positive patients receiving longterm ( $>3$ years) PPI therapy were exposed to a higher risk of developing enterochromaffin-like cell linear/micronodular hyperplasia and corpus atrophy, compared to $H$. pylorinegative patients [34]. No evidence of neoplastic changes was found. H. pylori eradication in infected long-term PPI users is an economically dominant strategy, significantly reducing symptom severity and overall healthcare costs [35].

Statement 7: ${ }^{13} \mathrm{C}$-urea breath test (UBT) is the preferred noninvasive method in the Greek population for H. pylori diagnosis.

Recommendation grade: $\boldsymbol{B}$; Evidence level: $2 \boldsymbol{b}$; Agreement level: $\mathbf{1 0 0 \%}$

Non-invasive methods include the stool antigen test (SAT), serology, and UBT. SAT detects $H$. pylori antigens in stool samples with a sensitivity and specificity up to $95 \%$ [36]; however, sample storage and transport may impair the sensitivity of the test. Taking also into account the unwillingness of patients in Greece to collect stool samples for testing, SAT is not the preferred method for adults. Serologic tests detect anti-H. pylori IgG antibodies with a variable sensitivity and specificity among the different manufacturers. Positive IgG serology indicates past, but not necessarily ongoing infection. The "cutoff" values of the serologic tests should be carefully determined in the local population before their widespread use in that population [37]. UBT requires the ingestion of a solution with urea labelled with either radioactive ${ }^{14} \mathrm{C}$ or non-radioactive ${ }^{13} \mathrm{C}$, followed by the detection of isotopelabelled carbon dioxide in a sample of collected exhaled breath air. A positive result indicates that $H$. pylori bacteria are present. The test is well-tolerated, easy to perform and has high diagnostic accuracy, with reported sensitivities and specificities $>90 \%$ in a recent meta-analysis [38]. The ${ }^{13} \mathrm{C}$ UBT has a higher diagnostic accuracy compared to serology and SATs [39]; it is therefore the recommended method for the non-endoscopic diagnosis of $H$. pylori infection in the Greek population. 
Statement 8: When an endoscopy is performed, the rapid urease test (RUT) should be preferred as the first diagnostic test for $H$. pylori detection. Two biopsies should be taken, one from the antrum and one from the corpus. A positive test permits the immediate initiation of treatment.

Recommendation grade: $\boldsymbol{B}$; Evidence level: $\mathbf{2} \boldsymbol{b}$; Agreement level: $\mathbf{8 6 \%}$

Interventional methods for $H$. pylori diagnosis demand biopsies taken during an esophagogastroduodenoscopy when indicated (see previous statements). The invasive methods which may be used for $H$. pylori diagnosis include RUT, histology, culture and polymerase chain reaction (PCR) [1]. In the case of RUT, and in order to increase the sensitivity and to reduce the time to positivity, it is preferable to put 2 biopsies into the reactive medium of RUT, 1 from the antrum and 1 from the corpus. Biopsies have to be taken from normal appearing mucosa, avoiding areas of ulceration and obvious IM where $H$. pylori is scarce or absent $[40,41]$. Recent use of antibiotics and/or bismuth compounds (4 weeks), as well as PPIs (2 weeks), increases the falsenegative results. Recent upper gastrointestinal bleeding also reduces RUT sensitivity [42]. False positive results due to other urease-containing organisms (e.g., Proteus spp.) are extremely rare, except in case of hypochlorhydria or achlorhydria [40]. While a negative RUT cannot exclude the presence of $H$. pylori, a positive test permits immediate treatment initiation.

Statement 9: Histochemical methods are considered the standard method for $H$. pylori detection. Immunohistochemistry can be helpful in cases of suspicion of $H$. pylori chronic gastritis when the microbe's presence cannot be confirmed by histochemical methods.

Recommendation Grade: A; Evidence level: $\mathbf{2} \boldsymbol{b}$; Agreement level: $\mathbf{1 0 0 \%}$

Severalmethodsandtechniques, includinghematoxylin and eosin (H\&E) stains, special stains and immunohistochemical stains, are available to pathologists for the detection of H. pylori in gastric biopsy specimens. Histochemical methods were and still are considered the reference method for $H$. pylori detection. Immunohistochemical staining is considered by many as the most sensitive and specific method of staining, and also the method with the lowest rate of interobserver variation [43]. However, the necessity for routine special stains and/or immunohistochemical stains has been debated in recent years. It is definitely easier to detect H. pylori using special stains, but is not cost-effective. Active H. pylori infection induces a chronic active inflammatory response with characteristic histomorphologic changes commonly observed with H\&E staining. Absence of chronic antral inflammation can be used as a surrogate marker to exclude $H$. pylori infection [44]. The presence of moderate to severe plasmacytic inflammation and the presence of moderate to severe neutrophilic infiltrate are sensitive and specific. It would be exceedingly unlikely to find a patient with $H$. pylori infection who does not have at least moderate plasmacytic infiltration (negative predictive value, 98\%) [45]. Immunohistochemistry should be reserved for unexplained gastritis and previously treated patients who are likely to have low bacterial density, and especially in gastric MALT lymphoma diagnosis and follow up [46].

Statement 10: $H$. pylori antimicrobial resistance can be determined by culture of $H$. pylori isolates from gastric biopsy specimens and/or molecular testing performed directly on gastric samples. When $H$. pylori is isolated, a gradient diffusion method (Epsilometer test, E-test) is currently recommended for the evaluation of $H$. pylori antimicrobial susceptibility.

Recommendation grade: $\boldsymbol{A}$; Evidence level: $\mathbf{1 b}$; Agreement level: $\mathbf{1 0 0 \%}$

Several methods exist for providing qualitative assessments to detect resistance in $H$. pylori culture isolates, including disk diffusion, agar dilution and gradient diffusion (E-test) [47]. The agar dilution method, although considered the reference method to which other techniques are compared, is labor-intensive and difficult to perform routinely [47]. The E-test has the advantage of being easy and reliable, with its results expressed as minimum inhibitory concentrations [48]. Several studies have reported an excellent correlation between this method and the agar dilution method [49], including studies from Greece [50,51]. One of the limitations of the E-test is that it is not widely available in Greece. Molecular methods offer an attractive approach for $H$. pylori identification and detection of antimicrobial susceptibility, providing rapid and accurate results, either on strains or directly on gastric biopsy specimens (fresh, frozen or paraffin-embedded). The 2 main methods used are real-time PCR and hybridization, with excellent specificity and sensitivity, greater than 95\% [52,53]. Clarithromycin resistance is associated with single-point mutations in the 23SrRNA gene, most commonly A2142C, A2142G and A2143G. The presence of mutations correlates very well with culture-based susceptibility testing [54]. Levofloxacin resistance is frequently related to point mutations in the DNA gyrase A subunit of the gyrA gene, and mainly involves substitutions at amino acid position 87 or 91 [55]. As opposed to phenotypic assays, molecular tests can be applied in biopsies with low bacterial load, and allow the detection of mixed populations (susceptible and resistant strains) [56]. However, they are also subject to limitations due to the variety of point mutations or genes associated with resistance, mainly to levofloxacin. 
Statement 11: ${ }^{13} \mathrm{C}$ UBT is the best method to confirm H. pylori eradication after treatment. When this is not available, SAT with monoclonal antibody is an alternative. If endoscopy is indicated, eradication should be confirmed not only by RUT, but also by histology of multiple biopsies.

Recommendation grade: A; Evidence level: 1a; Agreement level: $\mathbf{9 4 . 7 \%}$

The bacterial load after treatment may be low, and this may interfere with the sensitivity of methods that depend on the amount of tissue tested [57]. The RUT has a low sensitivity (up to $60 \%)$ for $H$. pylori detection after treatment [58-60]. The sensitivity of histology also depends on the site, number and size of biopsies, as well as pathologist experience. In contrast, the UBT and SAT have shown good results (sensitivity >90\%) as they reflect the whole gastric surface $[61,62]$. If endoscopy is indicated (gastric ulcer, MALT lymphoma, etc.) then multiple biopsies (Sydney protocol) should be taken to increase the sensitivity. Because of the high cost of histology, biopsies should not be taken if the only purpose is to confirm $H$. pylori eradication [6365]. UBT should be offered instead, and $H$. pylori eradication should be tested at least 2 weeks after PPI discontinuation and 4 weeks after stopping antibiotic and bismuth $[38,61]$. Serology is not indicated, because antibodies to $H$. pylori remain positive for a long period after eradication. Other invasive tests, such as culture and PCR, are also not indicated as confirmatory tests for H. pylori eradication in everyday clinical practice.

\section{B. H. pylori and extragastric-associated disorders}

Statement 12: A. The association between H. pylori infection and unexplained iron deficiency anemia (IDA) is supported in the literature. We propose that, after the exclusion of the etiologies most frequently associated with these disorders, $H$. pylori should be sought and treated.

Recommendation grade: $\boldsymbol{A}$; Level of Evidence: $\mathbf{1 c}$; Agreement Level: $\mathbf{8 4 . 6 \%}$

B. The association between H. pylori infection and unexplained idiopathic thrombocytopenic purpura (ITP) is supported in the literature. We propose that, after the exclusion of the etiologies most frequently associated with these disorders, H. pylori should be sought and treated.

Recommendation grade: $\boldsymbol{B}$; Level of Evidence: $3 \boldsymbol{a}$; Agreement Level: $\mathbf{8 4 . 6 \%}$

C. The association between H. pylori infection and unexplained vitamin B12 deficiency is supported in the literature. We propose that, after the exclusion of the etiologies most frequently associated with these disorders, H. pylori should be sought and treated.

Recommendation grade: $\boldsymbol{B}$; Level of Evidence: $3 \boldsymbol{a}$; Agreement Level: $\mathbf{8 4 . 6 \%}$
The association of $H$. pylori infection with otherwise unexplained IDA has been found in reviews and metaanalyses [66-68], but cohort studies did not support this association [69].

One meta-analysis [70] and 3 systematic reviews [68,71,72] demonstrated that $H$. pylori eradication induced a significant increase in platelet count in approximately half of ITPinfected patients, especially those with milder degrees of thrombocytopenia [71]; the prognosis of responders being excellent in the long term [68].

A systematic review and meta-analysis of 17 studies involving 2454 patients showed a significant reduction in serum levels of vitamin B12 in infected patients compared to non-infected [73]. However, serum vitamin B12 levels might increase following $H$. pylori eradication per se [74], or as a result of the consequent reduction of inflammation [75].

Statement 13: Several associations have been reported between $H$. pylori infection and Parkinson's disease and dementia. A connection has also been reported between H. pylori infection and chronic eye diseases, such as blepharitis, glaucoma, central serous chorioretinopathy and others. Evidence suggests that anti-H. pylori therapy may improve chronic urticaria and rosacea. Currently, any direct correlation of these diseases with $H$. pylori and its treatment should be treated with caution.

Recommendation grade: $\boldsymbol{B}$; Level of Evidence: $\mathbf{3} \boldsymbol{b}$; Agreement Level: $\mathbf{9 5 . 2} \%$

While there is some evidence of modification of the course of Parkinson's disease, there is no cure with treatment of the $H$. pylori infection [76]. Kountouras et al [77] reported a significantly higher prevalence of $H$. pylori infection in a Greek population with Alzheimer's disease (AD), with a higher prevalence of anti-H. pylori IgG in the cerebrospinal fluid of patients with $\mathrm{AD}$ [78] and an improvement in cognitive and functional status parameters during 2 years of follow up after successful eradication therapy [79]. However, most of the studies that reported a positive association of the infection with $\mathrm{AD}$ were published by the same group [77-79], while the treatment effect detected by Kountouras et al [79] has not yet been replicated elsewhere. The implication of this bacterium in chronic eye diseases, such as blepharitis, glaucoma, central serous chorioretinopathy and others, has also been hypothesized [80]. An association between $H$. pylori and chronic spontaneous urticaria has been reported and rosacea as an extraintestinal manifestation of $H$. pylori requires further research $[81,82]$.

Statement 14: The evidence available shows no causative association between $H$. pylori and cardiovascular disease (CVD). There are no convincing data that H. pylori eradication can reduce cardiovascular events.

Recommendation grade: $\boldsymbol{B}$; Level of Evidence: $3 \mathbf{a}$; Agreement Level: $\mathbf{8 9 . 5} \%$ 
An association between $H$. pylori in those infected with cytotoxin-associated gene A (CagA) and CVD or stroke has been suggested by meta-analyses of case-control studies [83-86]. Moreover, it has been proposed that IgG CagA positivity may predict prognosis after an ST-elevation myocardial infarction [87]. Based on these data, H. pylori eradication therapy was proposed as a cardiovascular prevention strategy [88]. However, to date there is insufficient direct evidence from prospective studies and RCTs that H. pylori eradication can reduce the incidence of CVD [89]. Moreover, there are studies that have failed to confirm a positive association. An inverse association between $H$. pylori infection and CVD mortality was found [90], especially among CagA-positive patients [91].

In a recent meta-analysis of 10 prospective observational studies evaluating the association between $H$. pylori infection and stroke no strong correlation was found, not even in those with CagA-positive infection [91].

Statement 15: A. Among different ethnic groups, there is a significant and persistent negative association between $H$. pylori infection and the development of inflammatory bowel disease (IBD).

Recommendation grade: B; Evidence level: $\mathbf{3 a}$; Agreement level: $\mathbf{9 1 . 7 \%}$

B. The role of H. pylori eradication in IBD is unknown.

Recommendation grade: C; Evidence level: 4; Agreement level: $\mathbf{9 1 . 7 \%}$

A negative association between $H$. pylori infection and IBD has been suggested and supported by many studies, including meta-analyses [92-97]; this association was stronger in CagApositive patients with Crohn's disease [92,93]. Data on the link between $H$. pylori eradication and IBD development are currently limited and inconclusive [98].
Statement 16: Other Helicobacter species cause gastric diseases in humans.

Recommendation grade: B; Evidence level: 2 ; Agreement level: $\mathbf{1 0 0 \%}$

Other non-H. pylori helicobacters (NHPH) have been identified in humans and, so far, the Helicobacter genus includes more than 30 formally named species [99]. Their occurrence in humans is low [100] compared to the occurrence of $H$. pylori [101]. Many of these helicobacters have been associated with diarrhea, others with bacteremia and systemic disease in immunocompromised hosts [102], whereas enterohepatic Helicobacter species such as $H$. bilis and $H$. hepaticus can colonize the biliary tract and have been associated with extrahepatic cholangiocarcinoma [103]. Gastric NHPH, such as $H$. suis, $H$. felis, $H$. bizzozeronii, $H$. heilmannii, and $H$. salomonis, have been detected in humans suffering from dyspepsia, epigastric pain or acid reflux [104,105], peptic ulcer [106], gastric cancer, and gastric MALT lymphoma [107]. Notably, the risk of developing gastric MALT lymphoma is higher during NHPH infection compared to infection with $H$. pylori. Eradication of these helicobacters by antimicrobial therapy has also resulted in the resolution of gastritis, peptic ulcer disease and clinical remission of MALT lymphoma [107].

Statement 17: H. pylori eradication therapy can alter the gut microbiota in the short as well as in the long term. The clinical significance of this modification is yet unclear.

Recommendation Grade: B; Evidence Level: $\mathbf{2} \boldsymbol{b}$; Agreement Level: $\mathbf{9 0 . 5 \%}$

Using culture-dependent and new culture-independent techniques, evidence is accumulating that the relative

Table 1 Recommendation grade and evidence level used at the Hellenic consensus on Helicobacter pylori infection. Adapted from Oxford Centre for Evidence-based Medicine-Levels of Evidence, March 2009 (https://www.cebm.net/2009/06/oxford-centre-evidence-based-medicine-levelsevidence-march-2009)

\begin{tabular}{|c|c|c|}
\hline Recommendation grade ${ }^{\star}$ & Evidence level & Study types \\
\hline A & $\begin{array}{l}1 \mathrm{a} \\
1 \mathrm{~b} \\
1 \mathrm{c}\end{array}$ & $\begin{array}{l}\text { Systematic review (with homogeneity) of randomized controlled trials } \\
\text { Randomized controlled trial with narrow confidence interval } \\
\text { Therapeutic results of the "all or nothing" type }\end{array}$ \\
\hline B & $2 \mathrm{a}$ & Systematic review (with homogeneity) of cohort studies \\
\hline & $\begin{array}{l}2 \mathrm{~b} \\
2 \mathrm{c} \\
3 \mathrm{a} \\
3 \mathrm{~b}\end{array}$ & $\begin{array}{l}\text { Cohort study (including a lower quality randomized clinical trial) } \\
\text { Observation of therapeutic results (outcomes research). Ecological study } \\
\text { Systematic review (with homogeneity) of case-control studies } \\
\text { Case-control study }\end{array}$ \\
\hline $\mathrm{C}$ & 4 & Case reports (including cohort or lower quality case-control) \\
\hline $\mathrm{D}$ & 5 & $\begin{array}{l}\text { Opinion lacking critical evaluation or based on basic matters (physiological study or anima } \\
\text { study) }\end{array}$ \\
\hline
\end{tabular}

\footnotetext{
* The grade of recommendation does not always correspond to the evidence level
} 
composition of intestinal microbiota (measured in stool samples before during and after eradication) changes as a result of eradication therapy and recovers to its pretreatment state after 4 to more than 9 weeks in the majority, but not all of the patients [108-110]. Probiotic supplementation slightly counteracts the pervasive effects of antibiotics on the intestinal microbiota (defined by fluorescence in situ hybridization and culture) [108]. Long-lasting perturbations of specific taxa (often beneficial) were also reported in recent studies using meta-genomic and genomic analyses [111-113]. The potential for inducing persistent macrolide resistance in the nostrils, throat and fecal microbiota following eradication therapy has been also reported [109].

\section{Treatment}

For eradication regimens currently commercially available in Greece, see the Supplementary Tables 1 and 2. It should be pointed out that bismuth salts and tetracycline or the combination drug ("Pylera") are not commercially available in our country.

Statement 18: Greece is a high $H$. pylori antibiotic resistance area for clarithromycin and metronidazole, with a prevalence that has far exceeded $20 \%$. Although the resistance rate of $H$. pylori isolates for levofloxacin is $<10 \%$, there is an increasing trend of levofloxacin resistance that jeopardizes its use.

Recommendation grade: $\boldsymbol{B}$; Evidence level: $2 \boldsymbol{b}$; Agreement level: $\mathbf{1 0 0 \%}$

Rapidly increasing antimicrobial resistance worldwide is the main factor contributing to the failure of eradication therapies [114]. Thus, $H$. pylori has recently been included in the World Health Organization's high-priority list of antibioticresistant bacteria [115]. The prevalence of antibiotic resistance varies among different geographical areas and has been shown to be associated with the consumption of antibiotics of the same family in those regions $[48,116]$. From this aspect, treatment recommendations based on a national consensus might be more helpful for local clinicians than those based on International consensuses [5,117].

Concerning Greece, the reported $H$. pylori resistance rates for adult patients range from $32-37 \%$ for metronidazole, 24$27 \%$ for clarithromycin, and $7-8 \%$ for levofloxacin $[48,118]$. Although resistance to metronidazole in Greece seems to have remained relatively stable, an increasing prevalence of $H$. pylori resistance to clarithromycin and levofloxacin over time has been reported $[118,119]$.

Data about secondary resistance are limited in Greece. In a study carried out in 2013, the reported values for metronidazole, clarithromycin and levofloxacin resistance were 50.6\%, 72.3\% and $15.6 \%$, respectively [120]. Amoxicillin and tetracycline currently seem to be untouched by the resistance problem in Greece.
Statement 19: H. pylori eradication rate is affected by antibiotic resistance, principally by clarithromycin and levofloxacin and to a lesser extent by metronidazole resistance. Thus, treatment recommendations should be based upon regional antibiotic resistance rates and individual consumption of antibiotics.

Recommendation grade: A; Evidence level: 1 ; Agreement level: $\mathbf{9 0 . 9 \%}$

The goal of a first-line treatment in patients with $H$. pylori infection is to reach $\geq 90 \%$ eradication rate, although this has rarely been achievable in real-world settings, especially in areas with high clarithromycin resistance $[121,122]$.

Many RCTs and meta-analyses have consistently shown that clarithromycin resistance has a detrimental effect on the efficacy of clarithromycin-containing regimens [123,124]. In contrast, metronidazole resistance can be partially overcome by increasing the dose, frequency, and treatment duration $[124,125]$.

It has been shown that, under the standard triple regimen, the mean eradication rate may be substantially lower (up to $70 \%)$ for clarithromycin-resistant strains [126,127]. In sequential regimens, clarithromycin resistance lowers the efficacy of 14 - and 10-day regimens by $31 \%$ and $33 \%$, respectively, whereas metronidazole resistance lowers the efficacy of 14- and 10-day regimens to a lesser extent (by $8 \%$ and 20\%, respectively) [128]. A concomitant regimen seems to perform better than a sequential one across different patterns of resistance [3] (see supplementary material of [3]). Eradication rates for isolated clarithromycin-resistant, isolated metronidazole-resistant and dual-resistant strains were: $71 \%$ vs. $87 \%, 86 \%$ vs. $98 \%$ and $47 \%$ vs. $78 \%$, respectively, for sequential vs. concomitant regimens [3]. A multicenter study from Greece, by Georgopoulos et al, has shown that clarithromycin resistance undermined both sequential and concomitant regimens, but the sequential regimen was additionally undermined by metronidazole resistance. Concomitant regimens achieved higher eradication rates than sequential ones of the same duration across all resistance patterns of $H$. pylori, but the difference reached statistical significance only in metronidazole-resistant strains [129].

Concerning hybrid therapy, in the only Greek study to present resistance data, eradication rates across different patterns of resistance were as follows: $97.8 \%$ in dual-sensitive, $90.5 \%$ in isolated metronidazole-resistant, $91.4 \%$ in isolated clarithromycin-resistant, and $50 \%$ in dual-resistant strains of H. pylori [130]. Moreover, dual resistance was the only factor that adversely affected the efficacy of this regimen in multivariate analysis [130]. As far as levofloxacin-based regimens are concerned, a systematic review with metaanalysis has shown that levofloxacin resistance may lower by about $45 \%$ the efficacy of a 7-14-day levofloxacin-based triple regimen (PPI sd bid, levofloxacin $500 \mathrm{mg}$ qd, amoxicillin $1 \mathrm{~g}$ bid). Mean eradication rate was $81.1 \%$ in susceptible vs. $36.3 \%$ in resistant strains [131]. 
To conclude, the $H$. pylori eradication rate is affected significantly by antibiotic resistance, principally by clarithromycin and levofloxacin and, to a lesser extent, by metronidazole resistance. Thus, treatment recommendations should be associated with the consumption of antibiotics of the same family in each region and with individual consumption of antibiotics. Concerning Greece, and based on reported data, a concomitant regimen seems to perform better than the standard triple, sequential and hybrid regimens, especially in dual-resistant $H$. pylori strains.

Statement 20: Standard triple therapy for a duration of 7-10 days can no longer be recommended as first-line treatment.

Recommendation grade: $\boldsymbol{A}$; Evidence level: $1 \boldsymbol{b}$; Agreement level: $\mathbf{1 0 0 \%}$

PPI triple therapies for 7-10 days were once standard and recommended as first-line therapy [132], but have since become increasingly ineffective [133]. A high clarithromycin resistance rate (over 20\%) [118] is the most important factor in reducing the efficacy of the standard triple regimen in Greece-which, according to the latest studies, varies around $75 \%$ [133,134]. Therefore, the triple regimen for 7-10 days should be abandoned as a first-line eradication regimen in Greece. In contrast, an optimized triple regimen (using a double dose of a new generation PPI for 14 days) has been proven effective in a Greek population with low clarithromycin resistance (8\%) [135], indicating that a 14-day optimized triple regimen could be used only in patients with a recent antibiotic susceptibility test (molecular or culture-based) demonstrating clarithromycin-susceptible $H$. pylori strains.

Statement 21: A concomitant non-bismuth quadruple regimen, for at least 10 days, is currently the preferred treatment option in Greece, providing acceptable eradication rates when used as first-line therapy.

Recommendation grade: A; Evidence level: $1 \boldsymbol{b}$; Agreement level: $100 \%$

In recent years, non-bismuth quadruple regimens have shown higher efficacy in many trials and are currently a viable option, especially in countries like Greece where bismuth is not available $[136,137]$. This finding was reproduced by 2 prospective randomized trials that compared concomitant and sequential regimens of the same duration (10 days) $[129,138]$. In both trials, a concomitant regimen reached an eradication rate of over $90 \%$ per protocol, significantly better compared to a sequential regimen, which had less than $85 \%$ efficacy. However, in another open-label controlled trial from Greece, even though the eradication rate for the concomitant regimen (over 90\%) was higher compared to the sequential (88\%), the difference did not reach statistical significance [139]. A sub- analysis linking outcomes with antibiotic resistance showed that the concomitant regimen performed significantly better in metronidazole-resistant strains [129]. This finding was also confirmed by a recent updated systematic review and metaanalysis comparing sequential vs. concomitant regimens [140]. In addition, in one RCT, an optimized 14-day sequential regimen containing a high dose of a second-generation PPI (esomeprazole $40 \mathrm{mg}$ bid) achieved high eradication rates in both per-protocol (93.9\%) and intention-to-treat (91.3\%) analyses in a population that included about $20 \%$ clarithromycin resistance [141]. However, a preliminary Greek study, published as an abstract and using a non-optimized 14-day sequential regimen, has recorded eradication rates $<90 \%$ with this regimen [142]. Thus, taking the above results together with the known level of metronidazole resistance in Greece (over 30\%), we recommend concomitant treatment for at least 10 days as the preferred choice for eradication of $H$. pylori, while the use of a 10-day sequential regimen should be discouraged.

Hybrid regimens are another type that proved their efficacy in a recent meta-analysis [143]. In 2 recently published Greek studies, an over $90 \%$ eradication rate in per-protocol analysis was proved $[129,142]$. As a result, currently a 14-day hybrid regimen should be used as an alternative to concomitant firstline treatment option, in Greece. Certainly, the use of national registries to continuously monitor treatment efficacy and safety in clinical practice is strongly recommended.

Statement 22: Fluoroquinolone-containing regimens should not be given as a first-line therapy.

Recommendation grade: A; Evidence level: 1c; Agreement level: $\mathbf{1 0 0 \%}$

The use of fluoroquinolone-containing regimens in firstline therapy should be discouraged [144]. The quinolonecontaining regimens have not reached the threshold of a $90 \%$ eradication rate, per protocol (or $80 \%$, intention to treat), in many studies as first- and second-line therapies [131,145]. They also have several, possibly severe, adverse effects, while an increasing rate of resistance to levofloxacin has recently been recorded in Greece [119]. Another observed fact was that the strategy of using a clarithromycin-containing therapy as initial treatment and a levofloxacin-containing therapy as rescue regimen achieved higher eradication rates than the opposite sequence [145]. Thus, it can be stated that fluoroquinolonecontaining regimens are not recommended as first-line but only as rescue therapies.

Statement 23: Extending the treatment duration to 14 days and enhancing acid suppression are strategies that might improve the outcome of certain eradication treatments.

Recommendation grade: A; Evidence level: 1c; Agreement level: $\mathbf{9 1 . 2 \%}$ 
Prolonging treatment duration has been suggested as a consistent strategy to improve the outcome of standard therapies. In a Greek randomized trial, extending the duration of triple therapy from 7 to 10 days was associated with an increase in eradication rates of about $6 \%$, while by prolonging treatment to 14 days a further boost of approximately $10 \%$ was obtained [135]. Accordingly, a meta-analysis of 19 studies confirmed a tendency toward better results with a 7-10 day (vs. 3-5 day) concomitant regimen, highlighting that the success of concomitant therapy may also be duration-dependent [146].

Effective acid suppression is also critical for $H$. pylori eradication, as it allows the bacteria to enter a replicative state, becoming susceptible to both amoxicillin and clarithromycin. Genetic variation in the activity of the cytochrome P450 (CYP) 2C19 (CYP2C19) is known to affect the plasma levels of PPIs, influencing the outcome of treatment [147]. A high proportion of extensive PPI metabolizers has been reported for North America and Europe. Thus, although the rate of rapid metabolizers in Greece is not precisely known, it is likely that a significant proportion of Greek patients require a higher PPI dose to control $\mathrm{pH}$ adequately. Nevertheless, the choice of a newer PPI and/or dose rather than CYP2C19 genotyping seems to be a more practical approach to assure the highest $H$. pylori eradication rates in clinical settings [148]. Recent data have shown that vonoprazan, a new and very effective potassium-competitive acid blocker, can significantly improve eradication rates when used in triple therapies instead of conventional PPIs [149]; however, so far, this agent has been approved for clinical use only in Japan. European studies determined the yield of so called "optimized" concomitant therapy in high-resistance settings [150]. In a landmark study, optimized concomitant and hybrid regimens have shown high eradication rates (over $90 \%$ per protocol) in populations of high clarithromycin resistance [151]. Concerning Greece, data suggest that enhancing acid suppression by using a high-dose, second-generation PPI (esomeprazole $40 \mathrm{mg}$ bid) is a well-suited approach, producing intention-to-treat efficacy above $[51,134,136]$ or close to [129] the boundary of $90 \%$ in a 10 -day regimen. In contrast, 10-day sequential therapy fails to achieve $80 \%$ (intention-to-treat) eradication, irrespective of whether a first- or second-generation PPI is included in the eradication scheme [129,138]. Recently, a 14day, high-dose esomeprazole hybrid therapy also displayed acceptable cure rates in Greece (intention-to-treat: $85.6 \%$, per protocol: 90.7\%) [130].

Furthermore, taking into account that the resistance of H. pylori to amoxicillin is exceptional, and the antibacterial activity of this drug is largely inhibited by gastric acidity. Dual combinations of various doses of amoxicillin (500 mg to $1 \mathrm{~g}$, tid or qid) with high-dose PPI (20-40 mg, tid or qid) have been tested in many countries (including Greece) as alternative therapeutic options, and have yielded highly heterogeneous results, with eradication rates ranging between $53.8 \%$ and 93.8\% [152-154]. Accordingly, although current evidence offers scant support, high-dose dual therapy for 14 days may be an option worth considering when multidrug-resistant H. pylori infection is suspected, such as in patients with multiple treatment failures [155].
Statement 24: Levofloxacin triple regimen for at least 10 days is recommended as the preferred second-line H. pylori treatment in Greece.

Recommendation grade: B; Evidence level: $3 \boldsymbol{a}$; Agreement level: $\mathbf{1 0 0 \%}$

Since 2010, bismuth has not been available on the Greek market. Therefore, the only available empirical treatment option for patients who have previously failed an $H$. pylori eradication therapy is a levofloxacin-containing triple regimen (standard dose PPI bid, levofloxacin $500 \mathrm{mg}$ qd, and amoxicillin $1 \mathrm{~g}$ bid, for 10-14 days) [3,131]. The efficacy of levofloxacincontaining regimens is highly affected by primary resistance to levofloxacin, acquired easily [131]. In countries with a high consumption of quinolones, the levofloxacin resistance rate is rapidly increasing [114]. Therefore, this drug has to be reserved for rescue treatment. According to one prospective study, PPI plus amoxicillin plus levofloxacin (PAL) as secondline therapy after the failure of concomitant treatment showed a $100 \%$ eradication rate in both per-protocol and intentionto-treat analyses [51]. However, after 2 previous H. pylori eradication failures, successful eradication was achieved by PAL in 21 of 30 patients (eradication rate $70 \%$ in both analyses) [133]. Concerning the optimal duration of treatment, eradication success seems to be significantly higher with 10 day compared to 7-day levofloxacin-containing regimens. Consequently, based on Greek studies and the regional level of levofloxacin resistance, currently below the critical limit of $10 \%[3,51,118,133,156,157]$, we suggest a levofloxacin-based triple regimen for at least 10 days as a sufficient (up to now) second-line treatment for $H$. pylori eradication in patients not previously treated with this antibiotic. Moreover, in light of the evidence for higher eradication rates with longer treatment durations, a 14-day regimen could also be an option [2]. Levofloxacin is generally well tolerated and most adverse effects associated with its use are transient and mild to moderate in severity [158].

Statement 25: In Greece, the eradication rate of bismuth quadruple therapy (BQT), when used as second-line treatment for 14 days, was sufficient.

Recommendation grade: $\boldsymbol{B}$; Evidence level: $2 \boldsymbol{b}$; Agreement level: $\mathbf{9 2 . 9 \%}$

BQT is effective in areas, like Greece, where there is increasing dual clarithromycin and metronidazole resistance, which has been shown to impact all non-bismuth quadruple therapies (sequential, concomitant, or hybrid therapy) $[127,131,159,160]$. This regimen is independent of clarithromycin resistance, while metronidazole resistance has limited clinical impact, especially after prolongation of treatment (14 days) and an increase in the dose of metronidazole (1500 mg per day) [152,161]. As mentioned above, bismuth 
salts and tetracycline have not been available on the Greek market for many years and recent nationwide data are lacking. When both bismuth salts and tetracycline were commercially available, BQT was used as a second- or third-line therapy. According to Greek studies [137,156,157,162-164], the eradication rates of $\mathrm{BQT}$ as second-line treatment, when used for 7-14 days, varied from $66.7-83.7 \%$ on intention-to-treat analysis and from $78.7-96 \%$ on per-protocol analysis. The unavailability of either tetracycline or bismuth salts in Greece, and the effectiveness of concomitant and levofloxacin triple therapy $[51,156,157]$ in the Greek population, relegate the use of BQT to third-line treatment. The use of a new formulation of a three-in-one mono-capsule, containing bismuth salts with metronidazole and tetracycline (licensed as "Pylera" in Europe) plus a PPI, achieved good compliance and optimal eradication rates $(>90 \%)$ where it was tested $[165,166]$.

Statement 26: Culture and antimicrobial susceptibility testing is not recommended before first-line therapy. Susceptibility-guided $H$. pylori therapy should be currently reserved as a rescue option, especially after a second-line treatment has failed.

Recommendation grade: C; Evidence level: 4; Agreement level: $\mathbf{8 1 . 3 \%}$

In contrast to the treatment of other bacterial infections, which involves the selection of an antibiotic based upon the organism's in vitro sensitivity, treatment of $H$. pylori has historically relied on empiric trials. This is because the systematic performance of endoscopy and H. pylori culture has several shortcomings: first, it is invasive and costly; second, it is time-consuming and complex to perform; and third, it might not completely reflect the in vivo susceptibility. At present, culture is performed in very few centers in Greece; thus, it is impractical or even unfeasible to recommend its routine use. Despite these limitations, the continuous rise in antibiotic resistance has prompted some experts to advocate universal pretreatment susceptibility testing in order to select the most effective therapy while minimizing the misuse of antibiotics [152,167]. However, a recent randomized study showed that susceptibility-guided therapy in a high resistance area was equally as effective as a local empirical regimen [168]. In addition, a recent randomized study failed to reveal superiority of genotypic resistance-guided therapy over a properly designed empirical treatment for eradication of refractory $H$. pylori infection [169].

Molecular testing methods such as PCR can be used to identify many of the mutations known to be responsible for antibiotic resistance [170]. These methods may revolutionize our approach to susceptibility-guided H. pylori therapy, allowing for non-invasive (fecal or other) and rapid characterization of genotypic resistance to clarithromycin (point mutations in the 23SrRNA gene) and fluoroquinolones (gyrase subunit A mutations) [171]. In contrast, no molecular test is available to test for metronidazole resistance, due to multiple and largely unknown mechanisms. A few available studies gathered data on the potential of a PCR-tailored approach and found promising results $[172,173]$. Interestingly, a Greek pilot study [174] determined remarkably high cure rates using a tailored 7-day triple regimen, in which selection of the key antibiotic (clarithromycin, levofloxacin, or rifabutin) relied on a PCR-based reverse hybridization assay. In the future, both clinical and economic evaluation data are awaited to better characterize the position of molecular testing in routine practice $[175,176]$.

Statement 27: Rifabutin should be reserved for third or subsequent treatment attempts.

Recommendation grade: $\boldsymbol{B}$; Evidence level: $2 \boldsymbol{a}$; Agreement level: $\mathbf{8 0 \%}$

There are no data from clinical trials conducted in our country that evaluated rifabutin in $H$. pylori eradication. The proven efficacy of rifabutin in the treatment of $H$. pylori infection should be balanced against its high cost, the risk of myelotoxicity (almost always reversible) and concerns about inducing resistance among Mycobacterium tuberculosis strains $[177,178]$. In a meta-analysis of cohort studies and cohort-type data from RCTs that used PPI plus amoxicillin plus rifabutin (PAR) as salvage treatment, pooled eradication rates were $79 \%$ (95\% confidence interval [CI] 67-92\%) as second-line, $66 \%(95 \%$ CI $55-77 \%)$ as third-line, and 70\% (95\%CI 60-79\%) as fourth- or fifth-line [178]. Rifabutin triple therapy is also effective in multidrug-resistant strains of $H$. pylori [179]. There is little evidence concerning the optimal duration for the PAR salvage treatment. It is notable that myelotoxicity, which can rarely complicate treatment with rifabutin, tends to occur with doses of greater than $600 \mathrm{mg}$ per day or with prolonged use. Thus, when rifabutin triple therapy is recommended, a dose of $300 \mathrm{mg}$ daily and a duration of 10 days would appear to be an appropriate choice [178].

Statement 28: In patients with documented penicillin allergy, a clarithromycin, fluoroquinolone-containing regimen may represent an initial empirical approach. Culture and an antimicrobial susceptibility test, if available, prior to any treatment attempt could be an alternative option.

Recommendation grade: $\mathbf{C}$; Evidence level: 4; Agreement level: $\mathbf{8 5 . 7 \%}$

H. pylori eradication is a challenge in patients allergic to penicillin. This leads to suboptimal choices and an increased risk of treatment failure using regimens that omit amoxicillin. It may be speculated that the rate of resistance to other antibiotics, different to $\beta$-lactam antibiotics, could be even higher in such patients, especially with regard to macrolides and particularly clarithromycin. Therefore, if the history is ambiguous, it seems 
appropriate to refer patients for allergy testing before any initial therapeutic approach, since the vast majority can ultimately be safely given amoxicillin-containing regimens [4]. There is a lack of data from clinical trials addressing the issue of $H$. pylori eradication in penicillin-allergic patients in Greece. Antibiotic susceptibility test and culture, if available, could be the initial approach; if not, the initial therapeutic step should be an empirical one. The substitution of metronidazole for amoxicillin in a triple combination (PPI-clarithromycin-metronidazole) is not an effective option, given the well-known prevalence of resistance to either or both antibiotics [118,180,181]. As empirical first-line treatment one could use the combination PPI-levofloxacin-clarithromycin for 10 days [180,181]. In case of failure of the first-line empiric therapeutic approach, then a 10- to 14-day bismuth quadruple regimen should be prescribed. The same approach can be used in the case of clarithromycin and/or levofloxacin resistance, if the initial workup was based on susceptibility testing by culture. As third- or fourth-line treatment after failed levofloxacin-based triple and bismuth-based quadruple therapies, a regimen including rifabutin (PPI-rifabutin-clarithromycin) for 10 days could be an alternative option. Moreover, since bismuth salts, tetracycline or the combination drug "Pylera" are not commercially available in Greece, if the initial empirical treatment attempts have failed, a bismuth-containing regimen that could be procured by IFET (Institute for Pharmaceutical Research and Technology) should be another option, especially if culture and antimicrobial susceptibility test are unavailable.

Statement 29: Only certain probiotic strains, including Lactobacillus, Bifidobacterium and Saccharomyces boulardii, may be potentially useful in reducing gastrointestinal side effects (mainly diarrhea), associated with $H$. pylori eradication therapies.

Recommendation grade: A; Evidence level: 1a; Agreement level: $\mathbf{8 8 . 9 \%}$

The most commonly studied probiotic species are the Lactobacillus, Bifidobacterium and Saccharomyces genera. Concerning the use of probiotics as a single therapy in H. pylori treatment, limited studies suggest that specific probiotics, such as Saccharomyces boulardii and Lactobacillus johnsonni La1, probably diminish the bacterial load, but do not completely eradicate the $H$. pylori infection [182]. A recent meta-analysis of RCTs, involving 4,515 patients, showed that the addition of probiotics to triple therapies significantly increased $H$. pylori eradication rates by $12.2 \%$ and $14.1 \%$, respectively [183]. Yet, other recent meta-analyses have been shown similarly good results by using probiotics as adjunctive to triple regimens [184]. On the contrary, another meta-analysis of 21 RCTs showed that a standard triple regimen plus probiotics may reduce the frequency of adverse events compared to the same triple regimen with or without placebo, but does not increase the eradication rate [185]. Moreover, when probiotics were added to quadruple eradication regimens, no additional benefit in $H$. pylori eradication rates was demonstrated, but only a reduction in the rate of adverse events [186]. More specifically, probiotics were shown to significantly decrease side effects such as nausea, vomiting, epigastric pain, and mainly diarrhea. One study analyzed the microbiome of patients receiving eradication treatment with or without the addition of probiotics and found a greater proportional shift in functional gene families in the group that received antibiotics only [187]. However, the beneficial effects of probiotics seem to be strain-, dose- and duration-specific, which could result in misleading conclusions [3]. Consequently, more data are definitely needed to assess the direct efficacy of probiotics against $H$. pylori.

\section{H. pylori and gastric malignancy}

Statement 30: H. pylori is considered the principal trigger for the development of gastric cancer.

Recommendation grade: A; Evidence level: 1a; Agreement level: $\mathbf{9 4 \%}$

The overall odds ratio for gastric cancer development in $H$. pylori-infected vs. $H$. pylori-uninfected persons was found to be 3.8 (95\%CI 2.3-6.2) [188]. Other less common causes account for only $3-5 \%$ of gastric adenocarcinomas, and include infection with the Epstein-Barr virus, inherited genetic abnormalities and autoimmune gastritis. Gastric cancer risk increases with infection with more virulent strains of $H$. pylori, such as CagA positive strains [189]. Importantly, all $H$. pylori strains cause gastric inflammation and disease. The difference in gastric cancer risk between the most- and the least-virulent strains is probably less than 3-fold, prompting the recommendation that all $H$. pylori infections be eradicated, irrespective of virulence factors [190].

Statement 31: Environmental factors, including salt, salted foods and smoking, are classified as probable risk factors for gastric cancer. The impact of excess alcohol drinking on gastric cancer development according to H. pylori infection status remains controversial. Fruit and non-starchy vegetables might protect against gastric cancer.

Recommendation grade: A; Evidence level: 1a; Agreement level: $\mathbf{1 0 0 \%}$

A large amount of evidence suggests that host diet and other environmental factors influence $H$. pylori-associated gastric cancer.

Dietary salts: Sheng et al found a direct association between salt intake and gastric cancer risk among the 11 studies included in their meta-analysis [191]. Another study also found that the consumption of salted fish, soy sauce, pickled vegetables, cured meat, and other salt-preserved foods 
increased the risk of gastric cancer via a synergic link to gastric atrophy [192]. Based on the available data, salt and salted foods have been classified as probable risk factors for gastric cancer, as well as food that could exacerbate gastritis [193].

Cigarette smoking: Many studies have demonstrated that cigarette smoking is associated with the risk of developing gastric cancer in $H$. pylori-infected subjects. Buckland et al constructed a healthy lifestyle index to investigate the joint influence of smoking, alcohol, certain dietary factors, and weight on gastric cancer risk within the European Prospective Investigation into Cancer and Nutrition (EPIC) cohort. The analysis included 461,550 participants (662 first incident gastric cancer cases) with a mean follow up of 11.4 years. A healthy lifestyle index was constructed. The authors found that the highest vs. the lowest score in the healthy lifestyle index was associated with a significant lower risk of gastric cancer by $51 \%$ overall, by $77 \%$ for cardia gastric cancer, and by $47 \%$ for noncardia gastric cancer. They calculated that $18.8 \%$ of all gastric cancer and $62.4 \%$ of cardia gastric cancer cases could have been prevented if participants had followed a healthy lifestyle behavior [194].

Alcohol consumption: The impact of excess alcohol drinking on gastric cancer development according to $H$. pylori infection status remains controversial. It seems, however, that it could have a harmful influence on gastric cancer development in conjunction with other unhealthy lifestyle behaviors [194].

Vegetables and fruits: The preventive role of the antioxidants contained in food, vegetables and fruits against gastric cancer has been proved in several studies. Some casecontrol studies from Europe, Asia, and North America suggest that intakes of both fruits and vegetables are protective against gastric cancer, reducing the risk by approximately $40 \%$ with the consumption of fruits and $30 \%$ by consuming vegetables [195]. A meta-analysis conducted by Lunet et al found overall weaker associations in the reduction in gastric cancer risk, from $18 \%$ for high intake of fruits to $12 \%$ for high intake of vegetables [196].

Statement 32: $H$. pylori infection is associated mainly with the intestinal type of gastric cancer through a cascade mechanism involving IM, dysplasia, and finally carcinogenesis. The diffuse type is more frequently related with a loss of expression of E-cadherin, rather than $H$. pylori infection.

Recommendation grade for intestinal type: A; Evidence level: 1a; Agreement level: $\mathbf{8 4 \%}$

Recommendation grade for diffuse type: B; Evidence level: 2a; Agreement level: $\mathbf{8 4 \%}$

The prolonged gastric inflammation resulting from chronic H. pylori infection may cause epithelial damage that leads to gastric atrophy characterized by a loss of parietal cells and chief cells, and glandular atrophy [197]. The diffuse subtype of gastric cancer appears to be more aggressive than the intestinal type. It is generally diagnosed in younger patients and no gender bias exists [198]. It can be associated with $H$. pylori infection, but in these cases there is the added impact of genetics: i.e., loss of expression of E-cadherin [199].

Statement 33: $H$. pylori eradication can reverse some pre-neoplastic lesions such as atrophy but not IM.

Recommendation grade: A; Evidence level: 1b; Agreement level: $\mathbf{9 0 \%}$

Three meta-analyses in 2007, 2011 and 2014 [200-202] showed an association of $H$. pylori eradication with histologic improvement in AG but not in IM. However, according to the Kyoto Consensus, H. pylori eradication cannot "reset the clock" to zero (i.e., no risk) but can stop the progression of risk and stabilize or decrease the subsequent risk [12]. Moreover, until now, Asian guidelines recommend $H$. pylori eradication in patients with AG and IM [203-205]. According to the European Union guidelines, the European Maastricht V Consensus, $H$. pylori eradication results in significant improvement in gastritis and AG but not in IM [3]. Finally, a recent metaanalysis (10 RCTs and 16 cohort studies with 52,363 subjects) suggested that patients with non-AG or AG benefited from $H$. pylori eradication for the risk of gastric cancer development, whereas those with IM or dysplasia did not. Hence, H. pylori eradication in patients who have already developed advanced pre-neoplastic lesions (i.e., IM or dysplasia) does not prevent the development of gastric cancer [206].

Statement 34: $H$. pylori "screen-and-treat" strategies are recommended in communities at high risk of gastric cancer.

Recommendation grade: A; Evidence level: 1a; Agreement level: $\mathbf{1 0 0 \%}$

Evidence suggests that $H$. pylori is the single most important etiological factor of gastric cancer, although in certain cases, such as cardia gastric cancer, some hereditary gastric cancers and cancers related to autoimmune gastritis, H. pylori seems not to be a necessary prerequisite [207]. Screen-and-treat strategies, with a large sample size and a sufficiently long follow-up period, have been conducted in a few countries, such as Taiwan [208], and China [209], and showed that such a strategy can prevent gastric cancer.

Statement 35: Screen-and-treat for $H$. pylori is recommended in individuals at increased risk for gastric cancer.

Recommendation grade: A; Evidence level: $2 a$; Agreement level: $\mathbf{1 0 0 \%}$

The increased prevalence of precancerous changes, such as atrophy and IM, in first-degree relatives of gastric cancer 
patients with $H$. pylori infection has been documented in several trials and in a meta-analysis [210,211]. Therefore, screening and treatment should be advised. Accordingly, immigrants from high-risk countries should be targeted and screened [212,213]. Noninvasive screening approaches for the identification of individuals at high risk for gastric cancer should be preferred on a population-wide basis to endoscopy ones. The noninvasive markers pepsinogen I, pepsinogen II and their ratio have been used as predictors of AG and IM, and their diagnostic accuracy has been assessed in a recent meta-analysis [214]. Accumulating data on biomarkers related with genetic variations and gastric cancer susceptibility will hopefully provide more useful screening tools in the future [215].

Statement 36: $H$. pylori eradication is associated with a significantly lower risk of gastric cancer, with significant implications for the prevention of this cancer. This benefit is maximized when $H$. pylori eradication is applied at early stages of the infection.

Recommendation grade: A; Evidence level: 1a; Agreement: 92\%

A growing body of evidence has suggested that H. pylori eradication might prevent the development of gastric cancer [216]. Thus, a systematic review and meta-analysis [206] (collaboration between Greece and Italy) of available studies was performed to update and better define the role of $H$. pylori eradication in preventing gastric cancer, with particular reference to patients with precancerous lesions (atrophy, IM, and dysplasia) at baseline histology. The risk of gastric cancer was significantly lower among patients with successfully eradicated $H$. pylori than among controls $(\mathrm{P}=0.00001)$. This finding applied separately for both RCTs $(\mathrm{P}=0.0009)$ and for cohort studies $(\mathrm{P}=0.00001)$. Concerning $H$. pylori eradication in patients with precancerous lesions, subgroup analyses showed that patients with non-AG or AG benefit from $H$. pylori eradication in terms of the risk of gastric cancer development, whereas those with IM or dysplasia do not. In conclusion, this meta-analysis showed that $H$. pylori eradication is associated with a significantly lower risk of gastric cancer, with significant implications for prevention of gastric cancer. This benefit is maximized when $H$. pylori eradication is applied at early stages of the infection, as was also suggested by another recent study [217].

Statement 37: H. pylori infection is accepted as the major etiological factor for localized early-stage gastric MALT lymphoma.

Recommendation grade: A; Evidence level: $1 \boldsymbol{b}$; Agreement level: $100 \%$

H. pylori infection is accepted as the major etiological factor for localized early-stage (Lugano I/II, Paris $\mathrm{T}_{1-4} \mathrm{~N}_{0-2} \mathrm{M}_{0-1}$ ) gastric MALT lymphoma [218]. Epidemiological, histomorphological, molecular, and experimental studies support the causative relation between the pathogen and gastric lymphomagenesis, and anti- $H$. pylori treatment should be offered as initial treatment to all patients [219]. Anti-H. pylori treatment is effective in approximately $60-80 \%$ of cases, thus providing another line of evidence for the association between $H$. pylori and MALT [220]. Patients with cytogenetic abnormalities, such as $\mathrm{t}(11 ; 18)(\mathrm{q} 21 ; \mathrm{q} 21)$ and $\mathrm{t}(1 ; 14)(\mathrm{p} 22 ; \mathrm{q} 32)$, are resistant to anti-H. pylori treatment and should be treated, after consultation with a hematologist/oncologist, with radiotherapy or chemotherapy [221-223]. Close endoscopic follow up is recommended after successful treatment, anti-microbial or other, given the fact that all patients carry precancerous lesions, such as gastric atrophy and IM, and are at increased risk for development of gastric adenocarcinoma [224].

Statement 38: The use of image-enhanced endoscopic technologies improves the detection of pre-neoplastic lesions of gastric mucosa and helps the targeted biopsies.

Recommendation grade: $\boldsymbol{B}$; Evidence level: $2 \boldsymbol{a}$; Agreement level: $77 \%$

The identification and surveillance of pre-neoplastic gastric lesions results in early detection of gastric cancer. Greek studies have shown that high-definition endoscopy and narrow-band imaging can efficiently detect gastric atrophy and IM $[225,226]$. A recent meta-analysis [227] showed that chromoendoscopy improves the detection of pre-neoplastic gastric lesions in comparison with white-light endoscopy. The pooled sensitivity was 0.90 (95\%CI $0.87-0.92)$ and specificity 0.82 (95\%CI 0.79-0.86) [227]. The existing data regarding the role of confocal laser endomicroscopy and auto-fluorescent imaging for the detection of pre-neoplastic lesions in the stomach, although promising, are inadequate to support their routine use [228].

Statement 39: OLGA and OLGIM staging systems are useful for gastric cancer risk stratification. Upper gastrointestinal surveillance endoscopy should be offered to patients with stage III and IV.

Recommendation grade: B; Evidence level: 2 c; Agreement level: $\mathbf{7 7 \%}$

Recent pathological guidelines recommend that the extent of atrophy and metaplasia must be explicitly described in histological reports [229,230]. OLGA (for Operative Link on Gastritis Assessment) is a system that classifies gastritis according to the extent of atrophy in the stomach: the more advanced the stage the more likely it is that a malignancy will develop [230,231]. Another system, considering IM instead of atrophy (OLGIM) was proposed later on and seems a little more precise than OLGA in predicting gastric cancer risk [232]. Surveillance is recommended for OLGA/OLGIM stages III and IV because patients with those stages of gastritis are at higher risk for gastric cancer development [233-235]. 


\section{Concluding remarks}

This is the first Hellenic consensus on H. pylori infection comprising 39 statements on 4 main topics, i.e., H. pylori diagnosis and association with diseases; H. pylori and gastric cancer; H. pylori and extra gastric associated disorders; and H. pylori treatment. The report summarizes the current concepts on these topics based on data derived from relevant medical literature and especially taking into account publications coming from Greek medical centers. It is expected that the recommendations and conclusions of this report will guide Greek physicians in their daily practice of managing $H$. pylori infection. As new data will becoming available from well-designed clinical trials these consensus statements might be regularly revised.

HELLENIC HELICOBACTER PYLORI CONSENSUS WORKING GROUP (in alphabetical order): Pericles Apostolopoulos, Aggeliki Christidou, Dimitrios Christodoulou, Sotirios D. Georgopoulos, Evangelos Giamarellos, Athanasios Giannakopoulos, Vassilios Govosdis, Panagiotis Kalapothakos, Dimitrios Kamberoglou, Dimitrios Kapetanos, Andreas Kapsoritakis, Georgios Karamanolis, Andreas Karameris, Stylianos Karatapanis, Panagiotis Kasapidis, Konstantinos Katsanos, Ioannis E. Koutroubakis, Stergios Kouvaras, Spyridon Ladas, Vasilis Leventogiannis, Christos Liatsos, Beatriz MartinezGonzalez, Nicoletta Mathou, Andreas Mentis, Spyridon Michopoulos, Konstantinos Mimidis, Vassilios Papastergiou, Kalliopi Petraki, Theodoros Rokkas, Dionysis Sgouras, Stavros Sougioultzis, Konstantinos Thomopoulos, Ioannis Triantafillidis, Konstantinos Triantafyllou, Dimitrios Tzilves, Maria Tzouvala, Nikolaos Viazis, Ioannis Vlachogiannakos, Elias Xirouchakis, Eva Zampeli, Christos Zavos.

\section{Acknowledgment}

We would like to acknowledge Mrs. Konstantina Tzogia for her generous secretarial support in the preparation of this manuscript.

\section{References}

1. Crowe SE. Clinical practice. Helicobacter pylori infection. $N$ Engl J Med 2019;380:1158-1165.

2. Fallone CA, Chiba N, van Zanten SV, et al. The Toronto consensus for the treatment of Helicobacter pylori infection in adults. Gastroenterology 2016;151:51-69.

3. Malfertheiner P, Megraud F, O'Morain CA, et al; European Helicobacter and Microbiota Study Group and Consensus panel. Management of Helicobacter pylori infection-the Maastricht V/Florence Consensus Report. Gut 2017;66:6-30.

4. Chey WD, Leontiadis GI, Howden CW, Moss. ACG clinical guideline: treatment of Helicobacter pylori infection. Am J Gastroenterol 2017;112:212-239

5. Liatsos C, Georgopoulos SD. Helicobacter pylori best treatment approach: should a national consensus be the best consensus? Ann
Gastroenterol 2017;30:704-706.

6. Apostolopoulos P, Vafiadis-Zouboulis I, Tzivras M, Kourtessas D, Katsilambros N, Archimandritis A. Helicobacter pylori (H. pylori) infection in Greece: the changing prevalence during a ten-year period and its antigenic profile. BMC Gastroenterol 2002;2:11.

7. Ford AC, Qume M, Moayyedi P, et al. Helicobacter pylori "test and treat" or endoscopy for managing dyspepsia: an individual patient data meta-analysis. Gastroenterology 2005;128:1838-1844.

8. Delaney B, Ford AC, Forman D, Moayyedi P, Qume M. Initial management strategies for dyspepsia. Cochrane Database Syst Rev 2005;4:CD001961.

9. Sugano K. Should we still subcategorize Helicobacter pyloriassociated dyspepsia as functional disease? J Neurogastroenterol Motil 2011;17:366-371.

10. Suzuki H, Moayyedi P. Helicobacter pylori infection in functional dyspepsia. Nat Rev Gastroenterol Hepatol 2013;10:168-174.

11. Sugano K, Tack J, Kuipers EJ, et al; faculty members of Kyoto Global Consensus Conference. Kyoto global consensus report on Helicobacter pylori gastritis. Gut 2015;64:1353-1367.

12. Stanghellini V, Chan FK, Hasler WL, et al. Gastroduodenal disorders. Gastroenterology 2016;150:1380-1392.

13. Mazzoleni LE, Sander GB, Francesconi CF, et al. Helicobacter pylori eradication in functional dyspepsia: HEROES trial. Arch Intern Med 2011;171:1929-1936.

14. Harvey RF, Lane JA, Nair P, et al. Clinical trial: prolonged beneficial effect of Helicobacter pylori eradication on dyspepsia consultations - the Bristol Helicobacter Project. Aliment Pharmacol Ther 2010;32:394-400.

15. Moayyedi P, Soo S, Deeks J, et al. Eradication of Helicobacter pylori for non-ulcer dyspepsia. Cochrane Database Syst Rev 2001;(2):CD002096.

16. Sostres C, Carrera-Lasfuentes P, Benito R, et al. Peptic ulcer bleeding risk. The role of Helicobacter pylori infection in NSAID/ low-dose aspirin users. Am J Gastroenterol 2015;110:684-689.

17. Papatheodoridis GV, Sougioultzis S, Archimandritis A. Effects of Helicobacter pylori and nonsteroidal anti-inflammatory drugs on peptic ulcer disease: a systematic review. Clin Gastroenterol Hepatol 2006;4:130-142.

18. Huang JQ, Sridhar S, Hunt RH. Role of Helicobacter pylori infection and non-steroidal anti-inflammatory drugs in peptic-ulcer disease: a meta-analysis. Lancet 2002;359:14-22.

19. Papatheodoridis GV, Papadelli D, Cholongitas E, Vassilopoulos D, Mentis A, Hadziyannis SJ. Effect of Helicobacter pylori infection on the risk of upper gastrointestinal bleeding in users of nonsteroidal anti-inflammatory drugs. Am J Med 2004;116:601-605.

20. Chan FK, To KF, Wu JC, et al. Eradication of Helicobacter pylori and risk of peptic ulcers in patients starting long-term treatment with non-steroidal anti-inflammatory drugs: a randomised trial. Lancet 2002;359:9-13.

21. de Leest HT, Steen KS, Lems WF, et al. Eradication of Helicobacter pylori does not reduce the incidence of gastroduodenal ulcers in patients on long-term NSAID treatment: double-blind, randomized, placebo-controlled trial. Helicobacter 2007;12:477-485.

22. Vergara M, Catalán M, Gisbert JP, Calvet X. Meta-analysis: role of Helicobacter pylori eradication in the prevention of peptic ulcer in NSAID users. Aliment Pharmacol Ther 2005;21:1411-1418.

23. Tang CL, Ye F, Liu W, Pan XL, Qian J, Zhang GX. Eradication of Helicobacter pylori infection reduces the incidence of peptic ulcer disease in patients using nonsteroidal anti-inflammatory drugs: a meta-analysis. Helicobacter 2012;17:286-296.

24. Fletcher EH, Johnston DE, Fisher CR, Koerner RJ, Newton JL, Gray CS. Systematic review: Helicobacter pylori and the risk of upper gastrointestinal bleeding risk in patients taking aspirin. Aliment Pharmacol Ther 2010;32:831-839.

25. Papatheodoridis GV, Archimandritis A. Role of Helicobacter pylori eradication in aspirin or non-steroidal anti-inflammatory drug 
users. World J Gastroenterol 2005;11:3811-3816.

26. Chan FK, Chung SC, Suen BY, et al. Preventing recurrent upper gastrointestinal bleeding in patients with Helicobacter pylori infection who are taking low-dose aspirin or naproxen. $N$ Engl $J$ Med 2001;344:967-973.

27. Lanza FL, Chan FK, Quigley EM; Practice Parameters Committee of the American College of Gastroenterology. Guidelines for prevention of NSAID-related ulcer complications. Am J Gastroenterol 2009;104:728-738.

28. Chan FK, Ching JY, Suen BY, Tse YK, Wu JC, Sung JJ. Effects of Helicobacter pylori infection on long-term risk of peptic ulcer bleeding in low-dose aspirin users. Gastroenterology 2013;144:528-535.

29. Leontiadis GI, Sreedharan A, Dorward S, et al. Systematic review of the clinical effectiveness and cost-effectiveness of proton pump inhibitors in acute upper gastrointestinal bleeding. Health Technol Assess 2007;11:iii-iv,1-164.

30. Song $\mathrm{H}$, Zhu J, Lu D. Long-term PPI use and the development of gastric pre-malignant lesions. Cochrane Database Syst Rev 2014;12:CD010623.

31. Ko Y, Tang J, Sanagapalli S, Kim BS, Leong RW. Safety of proton pump inhibitors and risk of gastric cancers: review of literature and pathophysiological mechanisms. Expert Opin Drug Saf 2016;15:53-63.

32. Fox JG, Kuipers EJ. Long-term proton pump inhibitor administration, $H$. pylori and gastric cancer: lessons from the gerbil. Gut 2011;60:567-568.

33. Wang J, Xu L, Shi R, et al. Gastric atrophy and intestinal metaplasia before and after Helicobacter pylori eradication: a meta-analysis. Digestion 2011;83:253-260.

34. Lundell L, Vieth M, Gibson F, Nagy P, Kahrilas PJ. Systematic review: the effects of long-term proton pump inhibitor use on serum gastrin levels and gastric histology. Aliment Pharmacol Ther 2015;42:649-663.

35. Mason JM, Raghunath AS, Hungin AP, Jackson W. Helicobacter pylori eradication in long-term proton pump inhibitor users is highly cost-effective: economic analysis of the HELPUP trial. Aliment Pharmacol Ther 2008;28:1297-1303.

36. Gisbert JP, de la Morena F, Abraira V. Accuracy of monoclonal stool antigen test for the diagnosis of $H$. pylori infection: a systematic review and meta-analysis. Am J Gastroenterol 2006;101:1921-1930.

37. Mentis A, Lehours P, Mégraud F. Epidemiology and diagnosis of Helicobacter pylori infection. Helicobacter 2015;20(Suppl 1):1-7.

38. Ferwana M, Abdulmajeed I, Alhajiahmed A, et al. Accuracy of urea breath test in Helicobacter pylori infection: meta-analysis. World J Gastroenterol 2015;21:1305-1314.

39. Best LM, Takwoingi Y, Siddique S, et al. Non-invasive diagnostic tests for Helicobacter pylori infection. Cochrane Database Syst Rev 2018;(3):CD012080

40. Uotani T, Graham DY. Diagnosis of Helicobacter pylori using the rapid urease test. Ann Transl Med 2015;3:9.

41. Michopoulos S, Sotiropoulou M, Vougadiotis I, et al. Does a second biopsy specimen increase CLO-test accuracy for Helicobacter pylori detection after eradication treatment in duodenal ulcer patients? Gut 1996;39(Suppl 3):A223.

42. Archimandritis A, Tzivras M, Sougioultzis S, et al. Rapid urease test is less sensitive than histology in diagnosing Helicobacter pylori infection in patients with non-variceal upper gastrointestinal bleeding. J Gastroenterol Hepatol 2000;15:369-373.

43. Anim JT, Al-Sobkie N, Prasad A, John B, Sharma PN, Al-Hamar I. Assessment of different methods for staining Helicobacter pylori in endoscopic gastric biopsies. Acta Histochem 2000;102:129-137.

44. Cutler AF, Havstad S, Ma CK, Blaser MJ, Perez-Perez GI, Schubert TT. Accuracy of invasive and non-invasive tests to diagnose Helicobacter pylori infection. Gastroenterology 1995;109:136-141.

45. Smith SB, Snow AN, Perry RL, et al. Helicobacter pylori: to stain or not to stain? Am J Clin Pathol 2012;137:733-738.
46. Wang XI, Zhang S, Abreo F, Thomas J. The role of routine immunohistochemistry for Helicobacter pylori in gastric biopsy. Ann Diagn Pathol 2010;14:256-259.

47. Mégraud F, Lehours P. Helicobacterpylori detection and antimicrobial susceptibility testing. Clin Microbiol Rev 2007;20:280-322.

48. Megraud F, Coenen S, Versporten A, et al; Study Group participants. Helicobacter pylori resistance to antibiotics in Europe and its relationship to antibiotic consumption. Gut 2013;62:34-42.

49. Glupczynski Y, Broutet N, Cantagrel A, et al. Comparison of the E test and agar dilution method for antimicrobial suceptibility testing of Helicobacter pylori. Eur J Clin Microbiol Infect Dis 2002;21:549-552.

50. Martinez-Gonzalez B, Georgopoulos SD, Xirouchakis E, Xirouchakis E, Sgouras D, Mentis A. Testing metronidazole susceptibility of Helicobacter pylori strains by the agar dilution reference method and Epsilometer test (E-test). Helicobacter 2015;20(Suppl 1):103.

51. Georgopoulos SD, Xirouchakis E, Martinez-Gonzalez B, et al. Clinical evaluation of a ten-day regimen with esomeprazole, metronidazole, amoxicillin, and clarithromycin for the eradication of Helicobacter pylori in a high clarithromycin resistance area. Helicobacter 2013;18:459-467.

52. Agudo S, Alarcón T, Urruzuno P, Martínez MJ, López-Brea M. Detection of Helicobacter pylori and clarithromycin resistance in gastric biopsies of pediatric patients by using a commercially available real-time polymerase chain reaction after NucliSens semi-automated DNA extraction. Diagn Microbiol Infect Dis 2010;67:213-219.

53. Oleastro M, Ménard A, Santos A, et al. Real-time PCR assay for rapid and accurate detection of point mutations conferring resistance to clarithromycin in Helicobacter pylori. J Clin Microbiol 2003;41:397-402.

54. Martinez-Gonzalez B, Papadakos K, Konstantoulaki C, et al. Determination of Helicobacter pylori clarithromycin resistance: Comparison of phenotypic culture method and molecular realtime PCR techniques. $17^{\text {th }}$ Hellenic Meeting for Helicobacter pylori, Athens National Research Foundation, 2012. p.156.

55. Glocker E, Kist M. Rapid detection of point mutations in the gyrA gene of Helicobacter pylori conferring resistance to ciprofloxacin by a fluorescence resonance energy transfer-based real-time PCR approach. J Clin Microbiol 2004;42:2241-2246.

56. Kalach N, Bontems P, Cadranel S. Advances in the treatment of Helicobacter pylori infection in children. Ann Gastroenterol 2015;28:10-18.

57. van der Wouden EJ, Thijs JC, van Zwet AA, Oey HB, Kleibeuker JH. Reliability of biopsy-based diagnostic tests for Helicobacter pylori after treatment aimed at its eradication. Eur J Gastroenterol Hepatol 1999;11:1255-1258.

58. el-Zimaity HM, al-Assi MT, Genta RM, Graham DY. Confirmation of successful therapy of Helicobacter pylori infection: number and site of biopsies or a rapid urease test. Am J Gastroenterol 1995;90:1962-1964.

59. Uotani T, Graham DY. Diagnosis of Helicobacter pylori using the rapid urease test. Ann Transl Med 2015;3:9.

60. Nishikawa K, Sugiyama T, Kato M, et al. A prospective evaluation of new rapid urease tests before and after eradication treatment of Helicobacter pylori, in comparison with histology, culture and 13C-urea breath test. Gastrointest Endosc 2000;51:164-168.

61. Gisbert JP, Pajares JM. Review article: 13C-urea breath test in the diagnosis of Helicobacter pylori infection - a critical review. Aliment Pharmacol Ther 2004;20:1001-1017.

62. Vaira D, Vakil N, Menegatti M, et al. The stool antigen test for detection of Helicobacter pylori after eradication therapy. Ann Intern Med 2002;136:280-287.

63. Laine L, Sugg J, Suchower L, Neil G. Endoscopic biopsy requirements for post-treatment diagnosis of Helicobacter pylori. 
Gastrointest Endosc 2000;51:664-669.

64. Lin MH, Cheng HT, Chuang WY, Yu LK, Tsou YK, Lee MS. Histological examination of ulcer margin for diagnosing Helicobacter pylori infection in patients with gastric ulcers. Ann Diagn Pathol 2013;17:63-66.

65. Michopoulos S, Balta A, Mentis A, et al. Invasive methods and clinical follow-up to estimate $H$. pylori eradication success. Gastroenterology 1998;114(Suppl 1):A227.

66. Hudac L, Jaraisy A, Haj S, et al. An updated systematic review and meta-analysis on the association between Helicobacter pylori infection and iron deficiency anemia. Helicobacter 2017; 22:e12330.

67. Yuan W, Li Yumin, Yang Kehu, et al. Iron deficiency anemia in Helicobacter pylori infection: meta-analysis of randomized controlled trials. Scand J Gastroenterol 2010;45:665-676.

68. Papagiannakis P, Michalopoulos C, Papalexi F, Dalampoura D, Diamantidis MD. The role of Helicobacter pylori infection in hematological disorders. Eur J Intern Med 2013;24:685-690.

69. Franceschi F, Gasbarrini A, Polyzos SA, Kountouras J. Extragastric diseases and Helicobacter pylori. Helicobacter 2015;20(Suppl 1):40-46.

70. Franchini M, Cruciani M, Mengoli C, Pizzolo G, Veneri D. Effect of Helicobacter pylori eradication on platelets count in idiopathic thrombocytopenic purpura: a systematic review and meta-analysis. J Antimicrob Chemother 2007;60:237-246.

71. Stasi R, Sarpatwari A,SegalJB, etal.Effects of eradication of Helicobacter pylori infection in patients with immune thrombocytopenic purpura: a systematic review. Blood 2009;113:1231-1240.

72. Vlachaki E, Agapidou A, Klonizakis P. Helicobacter pylori and immune thrombocytopenic purpura. Immunogastroenterology 2012;1:104-107.

73. Lahner E, Persechino S, Annibale B. Micronutrients (Other than iron) and Helicobacter pylori infection: a systematic review. Helicobacter 2012;17:1-15.

74. Serin E, Gumurdulu Y, Ozer B, Kayaselcuk F, Yilmaz U, Kocak R. Impact of Helicobacter pylori on the development of vitamin B12 deficiency in the absence of gastric atrophy. Helicobacter 2002;7:337-341.

75. Marino MC, de Oliveira CA, Rocha AM, et al. Long-term effect of Helicobacter pylori eradication on plasma homocysteine in elderly patients with cobalamin deficiency. Gut 2007;56:469-474.

76. Fasano A, Visanji NP, Liu LW, Lang AE, Pfeiffer RF. Gastrointestinal dysfunction in Parkinson's disease. Lancet Neurol 2015;14:625-639.

77. Kountouras J, Tsolaki M, Gavalas E, et al. Relationship between Helicobacter pylori infection and Alzheimer disease. Neurology 2006;66:938-940.

78. Kountouras J, Boziki M, Gavalas E, et al. Increased cerebrospinal fluid Helicobacter pylori antibody in Alzheimer's disease. Int $J$ Neurosci 2009;119:765-777.

79. Kountouras J, Boziki M, Gavalas E, et al. Eradication of Helicobacter pylori may be beneficial in the management of Alzheimer's disease. J Neurol 2009;256:758-767.

80. Kountouras J, Mylopoulos N, Boura P, et al. Relationship between Helicobacter pylori infection and glaucoma. Ophthalmology 2001; 108:599-604.

81. Bakos N, Fekete B, Prohászka Z, Füst G, Kalabay L. High prevalence of IgG and IgA antibodies to $19-\mathrm{kDa}$ Helicobacter pylori-associated lipoprotein in chronic urticaria. Allergy 2003;58:663-667.

82. Son SW, Kim IH, Oh CH, Kim JG. The response of rosacea to eradication of Helicobacter pylori. Br J Dermatol 1999;140:984-985.

83. Franceschi F, Niccoli G, Ferrante G, et al. CagA antigen of Helicobacter pylori and coronary instability: insight from a clinicopathological study and a meta-analysis of 4241 cases. Atherosclerosis 2009;202:535-542.

84. Zhang S, Guo Y, Ma Y, Teng Y. Relationship between the cytotoxinassociated gene-A status of $H$. pylori strains and cerebral infarction in European Caucasians and Chinese Han: a meta-analysis. World
J Gastroenterol 2008;14:1286-1292.

85. Sun J, Rangan P, Bhat SS, Liu L. A meta-analysis of the association between Helicobacter pylori infection and risk of coronary heart disease from published prospective studies. Helicobacter 2016;21:11-23.

86. Manolakis A, Kapsoritakis AN, Potamianos SP. A review of the postulated mechanisms concerning the association of Helicobacter pylori with ischemic heart disease. Helicobacter 2007;12:287-297.

87. Niccoli G, Roberto M, D’Amario D, et al. Cytotoxin-associated gene antigen-positive strains of Helicobacter pylori and recurring acute coronary syndromes. Eur Heart J Acute Cardiovasc Care 2017;6:535-544.

88. Kountouras J, Polyzos SA, Katsinelos P, et al. Cardio-cerebrovascular disease and Helicobacter pylori-related metabolic syndrome: We consider eradication therapy as a potential cardio-cerebrovascular prevention strategy. Int J Cardiol 2017;229:17-18.

89. Jiang J, Chen Y, Shi J, Song C, Zhang J, Wang K. Population attributable burden of Helicobacter pylori-related gastric cancer, coronary heart disease, and ischemic stroke in China. Eur J Clin Microbiol Infect Dis 2017;36:199-212.

90. Christodoulou D, Milionis H, Pappa P, et al. Association of Helicobacter pylori with cardiovascular disease-Is it just a myth? Eur J Intern Med 2011;22:191-194.

91. Yu M, Zhang Y, Yang Z, Ding J, Xie C, Lu N. Association between Helicobacter pylori infection and stroke: a meta-analysis of prospective observational studies. J Stroke Cerebrovasc Dis 2014;23:2233-2239.

92. Castaño-Rodríguez N, Kaakoush NO, Lee WS, Mitchell HM. Dual role of Helicobacter and Campylobacter species in IBD: a systematic review and meta-analysis. Gut 2017;66:235-249.

93. Tepler A, Narula N, Peek RM Jr, Patel A, Edelson C, Colombel JF, Shah SC. Systematic review with meta-analysis: association between Helicobacter pylori CagA seropositivity and odds of inflammatory bowel disease. Aliment Pharmacol Ther 2019 Jun 5. doi: 10.1111/apt.15306. Review.

94. Papamichael K, Konstantopoulos P, Mantzaris GJ. Helicobacter pylori infection and inflammatory bowel disease: is there a link? World J Gastroenterol 2014;20:6374-6385.

95. Rokkas T, Gisbert JP, Niv Y, O'Morain C. The association between Helicobacter pylori infection and inflammatory bowel disease based on meta-analysis. United European Gastroenterol J 2015;3:539-550.

96. Mantzaris GJ, Archavlis E, Zografos C, Zavos K, Petraki K, Triadaphyllou G. Low prevalence of Helicobacter pylori in inflammatory bowel disease: association with sulfasalazine. Am J Gastroenterol 1995;90:1900.

97. Triantafillidis JK, Gikas A, Apostolidis N, Merikas E, Mallas E, Peros G. The low prevalence of helicobacter infection in patients with inflammatory bowel disease could be attributed to previous antibiotic treatment. Am J Gastroenterol 2003;98:1213-1214.

98. Murad HA. Does Helicobacter pylori eradication therapy trigger or protect against Crohn's disease? Acta Gastroenterol Belg 2016;79:349-354.

99. Parte AC. LPSN-list of prokaryotic names with standing in nomenclature. Nucleic Acids Res 2014;42:D613-D616.

100. Øverby A, Murayama SY, Michimae H, et al. Prevalence of gastric non-Helicobacter pylori-Helicobacters in Japanese patients with gastric disease. Digestion 2017;95:61-66.

101. De Witte C, Schulz C, Smet A, Malfertheiner P, Haesebrouck F. Other Helicobacters and gastric microbiota. Helicobacter 2016;21(Suppl 1):62-68.

102. Nishida R, Shimono N, Miyake N, et al. Helicobacter cinaedi bacteremia mimicking a flare of systemic lupus erythematosus. Intern Med 2017;56:725-728.

103. Segura-López FK, Güitrón-Cantú A, Torres J. Association between Helicobacter spp. infections and hepatobiliary malignancies: a review. World J Gastroenterol 2015;21:1414-1423. 
104. Stolte M, Kroher G, Meining A, Morgner A, Bayerdörffer E, Bethke B. A comparison of Helicobacter pylori and H. heilmannii gastritis. A matched control study involving 404 patients. Scand J Gastroenterol 1997;32:28-33.

105. Yakoob J, Abbas Z, Khan R, et al. Prevalence of non-Helicobacter pylori species in patients presenting with dyspepsia. BMC Gastroenterol 2012;12:3.

106. Matsumoto T, Kawakubo M, Akamatsu T, et al. Helicobacter heilmannii sensu stricto-related gastric ulcers: a case report. World J Gastroenterol 2014;20:3376-3382.

107. Morgner A, Lehn N, Andersen LP, et al. Helicobacter heilmanniiassociated primary gastric low-grade MALT lymphoma: complete remission after curing the infection. Gastroenterology 2000;118:821-828.

108. Myllyluoma E, Ahlroos T, Veijola L, Rautelin H, Tynkkynen S, Korpela R. Effects of anti-Helicobacter pylori treatment and probiotic supplementation on intestinal microbiota. Int $J$ Antimicrob Agents 2007;29:66-72.

109. Jakobsson H, Wreiber K, Fall K, Fjelstad B, Nyrén O, Engstrand L. Macrolide resistance in the normal microbiota after Helicobacter pylori treatment. Scand J Infect Dis 2007;39:757-763.

110. Jakobsson HE, Jernberg C, Andersson AF, Sjölund-Karlsson M, Jansson JK, Engstrand L. Short-term antibiotic treatment has differing long-term impacts on the human throat and gut microbiome. PLoS One 2010;5:e9836.

111. Yap TW, Gan HM, Lee YP, et al. Helicobacter pylori eradication causes perturbation of the human gut microbiome in young adults. PLoS One 2016;11:e151893.

112. Li L, Zhou X, Xiao S, Ye F, Zhang G. The effect of Helicobacter pylori eradication on the gastrointestinal microbiota in patients with duodenal ulcer. J Gastrointestin Liver Dis 2016;25:139-146.

113. He C, Peng C, Wang H, Ouyang Y, Zhu Z, Shu X, Zhu Y, Lu N. The eradication of Helicobacter pylori restores rather than disturbs the gastrointestinal microbiota in asymptomatic young adults. Helicobacter 2019;24:e12590.

114. Thung I, Aramin H, Vavinskaya V, et al. Review article: the global emergence of Helicobacter pylori antibiotic resistance. Aliment Pharmacol Ther 2016;43:514-533.

115. Tacconelli E, Carrara E, Savoldi A, et al; WHO Pathogens Priority List Working Group. Discovery, research, and development of new antibiotics: the WHO priority list of antibiotic-resistant bacteria and tuberculosis. Lancet Infect Dis 2018;18:318-327.

116. Savoldi A, Carrara E, Graham DY, Conti M, Tacconelli E. Prevalence of antibiotic resistance in Helicobacter pylori: a systematic review and meta-analysis in World Health Organization regions. Gastroenterology 2018;155:1372-1382.

117. De Francesco V, Bellesia A, Ridola L, Manta R, Zullo A. First-line therapies for Helicobacter pylori eradication: a critical reappraisal of updated guidelines. Ann Gastroenterol 2017;30:373-379.

118. Martinez-Gonzalez B, Psarrakos P, Georgopoulos SD, et al. High incidence of Helicobacter pylori clarithromycin resistance in Greece. A three-year multicenter laboratory surveillance study. Helicobacter 2015;20(Suppl 1):100.

119. Karamanolis GP, Daikos GL, Xouris D, Goukos D, Delladetsima I, Ladas SD. The evolution of Helicobacter pylori antibiotics resistance over 10 years in Greece. Digestion 2014;90:229-231.

120. Martinez-Gonzalez B, Psarrakos P, Georgopoulos SD, et al. Primary and secondary antimicrobial resistance of Helicobacter pylori clinical isolates from Greek adult patients. Helicobacter 2013;18(Suppl 1):140.

121. Graham DY, Fischbach L. Helicobacter pylori treatment in the era of increasing antibiotic resistance. Gut 2010;59:1143-1153.

122. Liatsos C, Leontiadis GI. The "report card" to grade H. pylori treatment regimens: is it achievable in real-world in areas with high clarithromycin resistance? J Gastrointestin Liver Dis 2017;26:203-204.
123. Boltin D, Levi Z, Gingold-Belfer R, et al. Impact of previous exposure to macrolide antibiotics on Helicobacter pylori infection treatment outcomes. Am J Gastroenterol 2019;114:900-906.

124. Fischbach L, Evans EL. Meta-analysis: the effect of antibiotic resistance status on the efficacy of triple and quadruple firstline therapies for Helicobacter pylori. Aliment Pharmacol Ther 2007;26:343-357.

125. Puig I, Baylina M, Sánchez-Delgado J, et al. Systematic review and meta-analysis: triple therapy combining a proton-pump inhibitor, amoxicillin and metronidazole for Helicobacter pylori first-line treatment. J Antimicrob Chemother 2016;71:2740-2753.

126. Nyssen OP, McNicholl A, Megraud F, et al. Meta-analysis of sequential vs. standard triple therapy for Helicobacter pylori eradication: final results of a Cochrane systematic review. Cochrane Database Syst Rev 2016;28:CD009034.

127. Graham DY, Lee YC, Wu MS. Rational Helicobacter pylori therapy: evidence-based medicine rather than medicine-based evidence. Clin Gastroenterol Hepatol 2014;12:177-186.e3.

128. Liou JM, Chen CC, Chen MJ, et al; Taiwan Helicobacter Consortium. Sequential versus triple therapy for the first-line treatment of Helicobacter pylori: a multicentre, open-label, randomised trial. Lancet 2013;381:205-213.

129. Georgopoulos SD, Xirouchakis E, Martinez-Gonzales B, et al. Randomized clinical trial comparing ten day concomitant and sequential therapies for Helicobacter pylori eradication in a high clarithromycin resistance area. Eur J Intern Med 2016;32:84-90.

130. Georgopoulos SD, Papastergiou V, Martinez-Gonzalez B, et al. Hybrid therapy as first-line regimen for Helicobacter pylori eradication in a high clarithromycin resistance area: a prospective open-label trial. Ann Gastroenterol 2018;31:205-210.

131. Chen PY, Wu MS, Chen CY, et al; Taiwan gastrointestinal disease and Helicobacter consortium. Systematic review with metaanalysis: the efficacy of levofloxacin triple therapy as the first- or second-line treatments of Helicobacter pylori infection. Aliment Pharmacol Ther 2016;44:427-437.

132. Wurzer H, Rodrigo L, Stamler D, et al. Short-course therapy with amoxycillin-clarithromycin triple therapy for 10 days (ACT-10) eradicates Helicobacter pylori and heals duodenal ulcer. ACT-10 Study Group. Aliment Pharmacol Ther 1997;11:943-952.

133. Rokkas T, Sechopoulos P, Robotis I, Margantinis G, Pistiolas D. Cumulative $H$. pylori eradication rates in clinical practice by adopting first and second-line regimens proposed by the Maastricht III consensus and a third-line empirical regimen. Am J Gastroenterol 2009;104:21-25.

134. Georgopoulos S, Papastergiou V, Xirouchakis E, et al. Nonbismuth quadruple "concomitant" therapy versus standard triple therapy, both of the duration of 10 days, for first-line $H$. pylori eradication: a randomized trial. J Clin Gastroenterol 2013;47:228-232.

135. Karatapanis S, Georgopoulos SD, Papastergiou V, et al. "7, 10 and 14-days rabeprazole-based standard triple therapies for $H$. pylori eradication: are they still effective? A randomized trial". Acta Gastroenterol Belg 2011;74:407-412.

136. Georgopoulos S, Papastergiou V, Xirouchakis E, et al. Evaluation of a four-drug, three-antibiotic, non-bismuth-containing "concomitant" therapy as first-line Helicobacter pylori eradication regimen in Greece. Helicobacter 2012;17:49-53.

137. Georgopoulos SD, Papastergiou V, Karatapanis S. Current options for the treatment of Helicobacter pylori. Expert Opin Pharmacother 2013;14:211-223.

138. Apostolopoulos P, Koumoutsos I, Ekmektzoglou K, et al. Concomitant versus sequential therapy for the treatment of Helicobacter pylori infection: a Greek randomized prospective study. Scand J Gastroenterol 2016;51:145-151.

139. Ntouli V, Vrakas S, Koutoufaris G, et al. Efficacy and safety of Helicobacter pylori treatment in a Greek population. Helicobacter 
2016;21(Suppl 1):141.

140. Wang Y, Zhao R, Wang B, et al. Sequential versus concomitant therapy for treatment of Helicobacter pylori infection: an updated systematic review and meta-analysis. Eur J Clin Pharmacol 2018;74:1-13.

141. Liou JM, Chen CC, Fang YJ, et al; Members of the Taiwan Gastrointestinal Disease and Helicobacter Consortium. 14 day sequential therapy versus 10day bismuth quadruple therapy containing high-dose esomeprazole in the first-line and second-line treatment of Helicobacter pylori: a multicentre, non-inferiority, randomized trial. $J$ Antimicrob Chemother 2018;73:2510-2518.

142. Kalapothakos PN, Kourkoulis P, Koutoufaris G, et al. 14 day sequential or hybrid regimen for Helicobacter pylori eradication in clinical practice in southern Greece: a prospective pilot study. United European Gastroenterol J 2014;2(Suppl 1):A587.

143. Song ZQ, Liu J, Zhou LY. Hybrid therapy regimen for Helicobacter pylori eradication. Chin Med J (Engl) 2016;129:992-999.

144. Georgopoulos SD, Xirouchakis E. Which regimens should be used and which rejected for the treatment of Helicobacter pylori? Am J Gastroenterol 2017;112:1168-1169.

145. Liou JM, Lin JT, Chang CY, et al. Levofloxacin-based and clarithromycin-based triple therapies as first-line and secondline treatments for Helicobacter pylori infection: a randomised comparative trial with crossover design. Gut 2010;59:572-578.

146. Gisbert JP, Calvet X. Update on non-bismuth quadruple (concomitant) therapy for eradication of Helicobacter pylori. Clin Exp Gastroenterol 2012;5:23-34.

147. Furuta T, Shirai N, Takashima M, et al. Effect of genotypic differences in CYP2C19 on cure rates for Helicobacter pylori infection by triple therapy with a proton pump inhibitor, amoxicillin, and clarithromycin. Clin Pharmacol Ther 2001;69:158-168.

148. Graham DY, Lu H, Dore MP. Relative potency of proton-pump inhibitors, Helicobacter pylori therapy cure rates, and meaning of double-dose PPI. Helicobacter 2019;24:e12554.

149. Li M, Oshima T, Horikawa T, et al. Systematic review with metaanalysis: Vonoprazan, a potent acid blocker, is superior to protonpump inhibitors for eradication of clerithromycin-resistant strains of Helicobacter pylori. Helicobacter 2018;23:e12495.

150. Georgopoulos SD, Papastergiou V, Karatapanis S. Treatment of Helicobacter pylori infection: optimization strategies in a high resistance era. Expert Opin Pharmacother 2015;16:2307-2317.

151. Molina-Infante J, Romano M, Fernandez-Bermejo M, et al. Optimized non-bismuth quadruple therapies cure most patients with Helicobacter pylori infection in populations with high rates of antibiotic resistance. Gastroenterology 2013;145:121-128.e1.

152. Graham DY, Dore MP, Lu H. Understanding treatment guidelines with bismuth and non-bismuth quadruple Helicobacter pylori eradication therapies. Exp Rev Anti-infect Ther 2018;16:679-687.

153. Rokkas T, Mavrogeorgis A, Liatsos C, Rallis E, Kalogeropoulos N. Optimal dose of omeprazole in combination with amoxicillin in eradicating $H$. pylori and preventing relapses in duodenal ulcer patients. Hepatogastroenterology 1995;42:842-846.

154. Zullo A, Ridola L, Francesco VD, et al. High-dose esomeprazole and amoxicillin dual therapy for first-line Helicobacter pylori eradication: a proof of concept study. Ann Gastroenterol 2015;28:448-451.

155. Gao CP, Zhou Z, Wang JZ, Han SX, Li LP, Lu H. Efficacy and safety of high-dose dual therapy for Helicobacter pylori rescue therapy: A systematic review and meta-analysis. J Dig Dis 2016;17:811-819.

156. Karatapanis S, Skorda L, Georgopoulos S, et al. Levofloxacinbased triple therapy versus bismuth-based quadruple therapy as a second line treatment for the eradication of $H$. pylori infection. Ann Gastroenterol 2009;22:263-267.
157. Michopoulos S, Zambeli E, Argyriou K, et al. Second line levofloxacin-based triple therapies provide similar H. pylori eradication rates to bismuth-based quadruple therapies. United European Gastroenterol J 2014;2(Suppl 1):A588.

158. Chuah SK, Tai WC, Hsu PI, et al. The efficacy of second-line anti-Helicobacter pylori therapy using an extended 14-day levofloxacin/amoxicillin/proton-pump inhibitor treatment-a pilot study. Helicobacter 2012;17:374-381.

159. Georgopoulos SD, Xirouchakis E, Mentis A. Is there a nonbismuth quadruple therapy that can reliably overcome bacterial resistance? Gastroenterology 2013;145:1496-1497.

160. Papastergiou V, Georgopoulos SD, Karatapanis S. Treatment of Helicobacter pylori infection: meeting the challenge of antimicrobial resistance. World J Gastroenterol 2014;20:9898-9911.

161. Yeo YH, Hsu CC, Lee CC, et al. Systematic review with network meta-analysis: Effectiveness of therapies for secondline Helicobacter pylori eradication. J Gastroenterol Hepatol 2019;34:59-67.

162. Michopoulos S, Tsibouris P, Bouzakis H, et al. Randomized study comparing omeprazole with ranitidine as anti-secretory agents combined in quadruple second-line Helicobacter pylori eradication regimens. Aliment Pharmacol Ther 2000;14:734-744.

163. Georgopoulos SD, Ladas SD, Karatapanis S, et al. Effectiveness of two quadruple, tetracycline- or clarithromycin-containing, second-line, Helicobacter pylori eradication therapies. Aliment Pharmacol Ther 2002;16:569-575.

164. Mantzaris GJ, Petraki C, Petraki K, et al. Prospective, randomized study of seven versus fourteen day omeprazole quadruple therapy for eradication of Helicobacter pylori infection in patients with duodenal ulcer after failure of omeprazole triple therapy. Ann Gastroenterol 2005;18:330-335.

165. Malfertheiner P, Bazzoli F, Delchier JC, et al; Pylera Study Group. Helicobacter pylori eradication with a capsule containing bismuth subcitrate potassium, metronidazole, and tetracycline given with omeprazole versus clarithromycin-based triple therapy: a randomised, open-label, non-inferiority, phase 3 trial. Lancet 2011;377:905-913.

166. Fiorini G, Saracino IM, Zullo A, Gatta L, Pavoni M, Vaira D. Rescue therapy with bismuth quadruple regimen in patients with Helicobacter pylori-resistant strains. Helicobacter 2017;22.

167. Shiotani A, Lu H, Dore MP, Graham DY. Treating Helicobacter pylori infection while minimizing misuse of antibiotics. Cleve Clin J Med 2017;84:310-318.

168. Chen Q, Long X, Ji Y, et al. Randomised controlled trial: susceptibility-guided therapy versus empiric bismuth quadruple therapy for first-line Helicobacter pylori treatment. Aliment Pharmacol Ther 2019;49:1385-1394.

169. Liou JM, Chen PY, Luo JC, et al. Efficacies of genotypic resistanceguided vs empirical therapy for refractory Helicobacter pylori infection. Gastroenterology 2018;155:1109-1119.

170. Lehours P, Siffré E, Mégraud F. DPO multiplex PCR as an alternative to culture and susceptibility testing to detect Helicobacter pylori and its resistance to clarithromycin. BMC Gastroenterol 2011;11:112.

171. Papastergiou V, Georgopoulos SD, Karatapanis S. Treatment of Helicobacter pylori infection: Past, present and future. World J Gastrointest Pathophysiol 2014;5:392-399.

172. Liou JM, Chen CC, Chang CY, et al; Taiwan Helicobacter Consortium. Efficacy of genotypic resistance-guided sequential therapy in the third-line treatment of refractory Helicobacter pylori infection: a multicentre clinical trial. J Antimicrob Chemother 2013;68:450-456.

173. Liu Q, Qi D, Kang J, et al. Efficacy of real-time PCR-based detection of Helicobacter pylori infection and genotypic resistance-guided quadruple therapy as the first-line treatment for functional dyspepsia with Helicobacter pylori infection. Eur J 
Gastroenterol Hepatol 2015;27:221-225.

174. Papastergiou V, Mathou N, Licousi S, et al. Seven-day genotypic resistance-guided triple Helicobacter pylori eradication therapy can be highly effective. Ann Gastroenterol 2018;31:198-204.

175. Papastergiou V, Georgopoulos SD, Karatapanis S. Current and future insights in $H$. pylori eradication regimens: the need of tailoring therapy. Curr Pharm Des 2014;20:4521-4532.

176. Liou JM, Chen PY, Kuo YT, Wu MS. Taiwan Gastrointestinal Disease and Helicobacter Consortium. Toward population specific and personalized treatment of Helicobacter pylori infection. J Biomed Sci 2018;25:70.

177. Liu X, Wang H, Lv Z, et al. Rescue therapy with a proton pump inhibitor plus amoxicillin and rifabutin for Helicobacter pylori infection: a systematic review and meta-analysis. Gastroenterol Res Pract 2015;2015:415-648.

178. Gisbert JP, Calvet X. Review article: rifabutin in the treatment of refractory Helicobacter pylori infection. Aliment Pharmacol Ther 2012;35:209-221.

179. Fiorini G, Zullo A, Vakil N, et al. Rifabutin triple therapy is effective in patients with multidrug-resistant strains of Helicobacter pylori. J Clin Gastroenterol 2018;52:137-140.

180. Gisbert JP, Pérez-Aisa A, Castro-Fernández M, et al. Helicobacter pylori first-line treatment and rescue option containing levofloxacin in patients allergic to penicillin. Dig Liver Dis 2010;42:287-290.

181. Gisbert JP, Barrio J, Modolell I, et al. Helicobacter pylori first-line and rescue treatments in the presence of penicillin allergy. Dig Dis Sci 2015;60:458-464.

182. Losurdo G, Cubisino R, Barone M, et al. Probiotic monotherapy and Helicobacter pylori eradication: a systematic review with pooled-data analysis. World J Gastroenterol 2018;24:139-149.

183. Lau CS, Ward A, Chamberlain RS. Probiotics improve the efficacy of standard triple therapy in the eradication of Helicobacter pylori: a meta-analysis. Infect Drug Resist 2016;9:275-289.

184. McFarland LV, Huang Y, Wang L, Malfertheiner P. Systematic review and meta-analysis: Multi-strain probiotics as adjunct therapy for Helicobacter pylori eradication and prevention of adverse events. United European Gastroenterol J 2016;4:546-561.

185. Lu C, Sang J, He H, et al. Probiotic supplementation does not improve eradication rate of Helicobacter pylori infection compared to placebo based on standard therapy: a meta-analysis. Sci Rep 2016;6:23522.

186. Shavakhi A, Tabesh E, Yaghoutkar A, et al. The effects of multistrain probiotic compound on bismuth-containing quadruple therapy for Helicobacter pylori infection: a randomized placebocontrolled triple-blind study. Helicobacter 2013;18:280-284.

187. Oh B, Kim BS, Kim JW, et al. The effect of probiotics on gut microbiota during the Helicobacter pylori eradication: randomized controlled trial. Helicobacter 2016;21:165-174.

188. Forman D, Webb P, Parsonnet J. H. pylori and gastric cancer. Lancet 1994;343:243-244.

189. Huang JQ, Zheng GF, Sumanac K, Irvine EJ, Hunt RH. Meta-analysis of the relationship between cagA seropositivity and gastric cancer. Gastroenterology 2003;125:1636-1644.

190. Yamaoka Y, Graham DY. Helicobacter pylori virulence and cancer pathogenesis. Future Oncol 2014;10:1487-1500.

191. Sheng Ge S, Feng X, Shen L, Wei Z, Zhu Q, Sun J. Association between habitual dietary salt intake and risk of gastric cancer: a systematic review of observational studies. Gastroenterol Res Pract 2012;2012:808120.

192. Wang XQ, Terry PD, Yan H. Review of salt consumption and stomach cancer risk: epidemiological and biological evidence. World J Gastroenterol 2009;15:2204-2213.

193. World Cancer Research Fund/American Institute for Cancer Research. Food, Nutrition, Physical Activity and the Prevention of Cancer: A Global Perspective World Cancer Research Fund. Washington, DC: American Institute for Cancer Research, 2007.

194. Buckland G, Travier N, Huerta JM, et al. Healthy lifestyle index and risk of gastric adenocarcinoma in the EPIC cohort study. Int J Cancer 2015;137:598-606.

195. Lunet N, Valbuena C, Vieira AL, et al. Fruit and vegetable consumption and gastric cancer by location and histological type: case-control and meta-analysis. Eur $J$ Cancer Prev 2007;16:312-327.

196. Lunet N, Lacerda-Vieira A, Barros H. Fruit and vegetables consumption and gastric cancer: a systematic review and metaanalysis of cohort studies. Nutr Cancer 2005;53:1-10.

197. Piazuelo MB, Correa P. Gastric cancer: overview. Colomb Med (Cali) 2013;44:192-201.

198. Henson DE, Dittus C, Younes M, Nguyen H, Albores-Saavedra J. Differential trends in the intestinal and diffuse types of gastric carcinoma in the United States, 1973-2000: increase in the signet ring cell type. Arch Pathol Lab Med 2004;128:765-770.

199. Barber M, Murrell A, Ito Y, et al. Mechanisms and sequelae of E-cadherin silencing in hereditary diffuse gastric cancer. J Pathol 2008;216:295-306.

200. Rokkas T, Pistiolas D, Sechopoulos P, Robotis I, Margantinis G. The long-term impact of Helicobacter pylori eradication on gastric histology: a systematic review and meta-analysis. Helicobacter 2007;12(Suppl 2):32-38.

201. Wang J, Xu L, Shi R, et al. Gastric atrophy and intestinal metaplasia before and after Helicobacter pylori eradication: a meta-analysis. Digestion 2011;83:253-260.

202. Kong YJ, Yi HG, Dai JC, Wei MX. Histological changes of gastric mucosa after Helicobacter pylori eradication: a systematic review and meta-analysis. World J Gastroenterol 2014;20:5903-5911.

203. Kim SG, Jung HK, Lee HL, et al; Korean College of Helicobacter and Upper Gastrointestinal Research. Guidelines for the diagnosis and treatment of Helicobacter pylori infection in Korea, 2013 revised edition. Korean J Gastroenterol 2013;62:3-26.

204. Liu WZ, Xie Y, Lu H, et al. Fifth Chinese National Consensus Report on the management of Helicobacter pylori infection. Chinese Society of Gastroenterology, Chinese Study Group on Helicobacter pylori and Peptic Ulcer. Helicobacter 2018;23:e12475.

205. Kato M, Ota H, Okuda M, et al. Guidelines for the management of Helicobacter pylori infection in Japan: 2016 Revised Edition. Helicobacter 2019; 12597.

206. Rokkas T, Rokka A, Portincasa P. A systematic review and meta-analysis of the role of Helicobacter pylori eradication in preventing gastric cancer. Ann Gastroenterol 2017;30;414-423.

207. Malfertheiner P, Sipponen P, Naumann M, et al; Lejondal H. pylori-Gastric Cancer Task Force. Helicobacter pylori eradication has the potential to prevent gastric cancer: a state-ofthe-art critique. Am J Gastroenterol 2005;100:2100-2115.

208. Yoon H, Kim N. Diagnosis and management of high risk group for gastric cancer. Gut Liver 2015;9:5-17.

209. Lin JT. Screening of gastric cancer: who, when, and how. Clin Gastroenterol Hepatol 2014;12:135-138.

210. Oh S, Kim N, Yoon H, et al. Risk factors of atrophic gastritis and intestinal metaplasia in first-degree relatives of gastric cancer patients compared with age-sex matched controls. J Cancer Prev 2013;18:149-160.

211. Rokkas T, Sechopoulos P, Pistiolas D, Margantinis G, Koukoulis G. Helicobacter pylori infection and gastric histology in first-degree relatives of gastric cancer patients: a meta-analysis. Eur J Gastroenterol Hepatol 2010;22:1128-1133.

212. Arnold M, Moore SP, Hassler S, Ellison-Loschmann L, Forman D, Bray $\mathrm{F}$. The burden of stomach cancer in indigenous populations: a systematic review and global assessment. Gut 2014;63:64-71.

213. De Vries AC, Van Driel HF, Richardus JH, et al. Migrant 
communities constitute a possible target population for primary prevention of Helicobacter pylori-related complications in low incidence countries. Scand J Gastroenterol 2008;43:403-409.

214. Huang YK, Yu JC, Kang WM, et al. Significance of serum pepsinogens as a biomarker for gastric cancer and atrophic gastritis screening: a systematic review and meta-analysis. PLoS One 2015;10:e142080.

215. Mocellin S, Verdi D, Pooley KA, Nitti D. Genetic variation and gastric cancer risk: a field synopsis and meta-analysis. Gut 2015;64:1209-1219.

216. Ford AC, Forman D, Hunt RH, Yuan Y, Moayyedi P. Helicobacter pylori eradication therapy to prevent gastric cancer in healthy asymptomatic infected individuals: systematic review and metaanalysis of randomised controlled trials. BMJ 2014;20:348:g3174.

217. Leung WK, Wong IOL, Cheung KS, et al. Effects of Helicobacter pylori treatment on incidence of gastric cancer in older individuals. Gastroenterology 2018;155:67-75.

218. Kalpadakis C, Pangalis GA, Vassilakopoulos TP, et al. Clinical aspects of malt lymphomas. Curr Hematol Malig Rep 2014;9:262-272.

219. Wotherspoon AC, Ortiz-Hidalgo C, Falzon MR, Isaacson PG. Helicobacter pylori-associated gastritis and primary B-cell gastric lymphoma. Lancet 1991;338:1175-1176.

220. Fischbach W, Goebeler-Kolve ME, Dragosics B, Greiner A, Stolte M. Long term outcome of patients with gastric marginal zone B cell lymphoma of mucosa associated lymphoid tissue (MALT) following exclusive Helicobacter pylori eradication therapy: experience from a large prospective series. Gut 2004;53:34-37.

221. Liu H, Ye H, Ruskone-Fourmestraux A, et al. $\mathrm{T}(11 ; 18)$ is a marker for all stage gastric MALT lymphomas that will not respond to H. pylori eradication. Gastroenterology 2002;122:1286-1294.

222. Ruskoné-Fourmestraux A, Fischbach W, Aleman BM, et al; EGILS group. EGILS consensus report. Gastric extranodal marginal zone B-cell lymphoma of MALT. Gut 2011;60:747-758.

223. Papaxoinis G, Fountzilas G, Rontogianni D, et al. Low-grade mucosa-associated lymphoid tissue lymphoma: a retrospective analysis of 97 patients by the Hellenic Cooperative Oncology Group (HeCOG). Ann Oncol 2008;19:780-786.

224. Fischbach W, Goebeler ME, Ruskone-Fourmestraux A, et al; EGILS (European Gastro-Intestinal Lymphoma Study) Group. Most patients with minimal histological residuals of gastric MALT lymphoma after successful eradication of Helicobacter pylori can be managed safely by a watch and wait strategy: experience from a large international series. Gut 2007;56:1685-1687.

225. Panteris V, Nikolopoulou S, Lountou A, Triantafillidis JK. Diagnostic capabilities of high-definition white light endoscopy for the diagnosis of gastric intestinal metaplasia and correlation with histologic and clinical data. Eur J Gastroenterol Hepatol 2014;26:594-601.

226. Xirouchakis E, Laoudi F, Tsartsali L, Georgopoulos SD. Screening for gastric premalignant lesions with narrow band imaging, white light and updated Sydney protocol or both? Dig Dis Sci 2013;58:1084-1990.

227. Zhao Z, Yin Z, Wang S, et al. Meta-analysis: The diagnostic efficacy of chromoendoscopy for early gastric cancer and premalignant gastric lesions. J Gastroenterol Hepatol 2016;31:1539-1545.

228. Kikuste I, Marques-Pereira R, Monteiro-Soares M, et al. Systematic review of the diagnosis of gastric premalignant conditions and neoplasia with high-resolution endoscopic technologies. Scand J Gastroenterol 2013;48:1108-1117229.

229. Rugge M, Genta RM, Group O. Staging gastritis: an international proposal. Gastroenterology 2005;129:1807e8.

230. Pimentel-Nunes P, Libânio DMarcos-Pinto R, et al. Management of precancerous conditions and lesions in the stomach (MAPS II): European Society of Gastrointestinal Endoscopy (ESGE), European Helicobacter and Microbiota Study Group (EHMSG), European Society of Pathology (ESP), and the Sociedade Portuguesa de Endoscopia Digestiva (SPED) guideline update 2019. Endoscopy 2019;51:365-388.

231. Rugge M, de Boni M, Pennelli G, et al. Gastritis OLGA-staging and gastric cancer risk: a twelve-year clinico-pathological follow- up study. Aliment Pharmacol Ther 2010;31:1104e11.

232. Capelle LG, de Vries AC, Haringsma J, et al. The staging of gastritis with the OLGIM system by using intestinal metaplasia as an accurate alternative for atrophic gastritis. Gastrointest Endosc 2010;71:1150e8.

233. Mera RM, Bravo LE, Camargo MC, et al. Dynamics of Helicobacter pylori infection as a determinant of progression of gastric precancerous lesions: a 16-year follow-up of an eradication trial. Gut 2018;67:1239-1246.

234. Yue H, Shan L, Bin L. The significance of OLGA and OLGIM staging systems in the risk assessment of gastric cancer: a systematic review and meta-analysis. Gastric Cancer 2018;21:579-587.

235. Rugge M, Meggio A, Pravadelli C, et al. Gastritis staging in the endoscopic follow-up for the secondary prevention of gastric cancer: a 5-year prospective study of 1755 patients. Gut 2019;68:11-17. 


\section{Supplementary Material}

\section{Eradication regimens currently available in Greece}

The eradication regimens for Helicobacter pylori (H. pylori) have continued to evolve over the past 20 years, with multiple regimens having been evaluated in randomized controlled trials. In addition, many national guidelines for $H$. pylori treatment have been published, highlighting the importance of differences in the effectiveness and availability among eradication regimens observed in different countries [1]. However, the optimal therapeutic regimen has not yet been defined. It has been suggested that the goal of $H$. pylori therapy should now be eradication in at least $90 \%$ of treated patients [2]. This arbitrary threshold is not easily achieved, especially in real-world settings [3]. However, the most efficacious therapies available should be used first, to avoid the cost, inconvenience, and risks associated with treatment failure.

The most common regimens for $H$. pylori eradication currently available in Greece are shown in Supplementary Table 1 and the suggested doses in Supplementary Table 2.

It should be noted that in Greece bismuth, tetracycline and furazolidone are not commercially available. Therefore, regimens containing these drugs are not so far applicable to Greek patients.

Supplementary Table 1 Regimens currently available in Greece

\begin{tabular}{|c|c|c|}
\hline Recommendation & Regimen & Definition \\
\hline \multicolumn{3}{|c|}{ First line } \\
\hline Recommended option & Concomitant (non-bismuth) quadruple (PAMC) & PPI + amoxicillin + metronidazole + clarithromycin \\
\hline Recommended option & Hybrid (non-bismuth) quadruple (PA followed by PAMC) & $\begin{array}{l}\text { PPI + amoxicillin followed by } \\
\text { PPI + amoxicillin + metronidazole + clarithromycin }\end{array}$ \\
\hline Not recommended & Sequential (non-bismuth) quadruple (PA followed by PMC) & $\begin{array}{l}\text { PPI + amoxicillin followed by } \\
\text { PPI + metronidazole + clarithromycin }\end{array}$ \\
\hline Not recommended & Triple (PAC, PMC or PAM) & $\begin{array}{l}\text { PPI + amoxicillin + clarithromycin } \\
\text { PPI + metronidazole + clarithromycin } \\
\text { PPI + amoxycillin + metronidazole }\end{array}$ \\
\hline
\end{tabular}

Prior treatment failure

\begin{tabular}{lll}
\hline Recommended option & Levofloxacin-containing therapy (usually PAL) & PPI + amoxicillin + levofloxacin \\
Recommended option & Moxifloxacin-containing therapy (usually PAM) & PPI + amoxicillin + moxifloxacin \\
Restricted option & Rifabutin-containing therapy (usually PAR) & PPI + amoxicillin + rifabutin \\
\hline PPI, proton pump inhibitor & &
\end{tabular}

Supplementary Table 2 Recommendations for dose of agents available in Greece, used for Helicobacter pylori eradication therapy

Doses for agents in all regimens

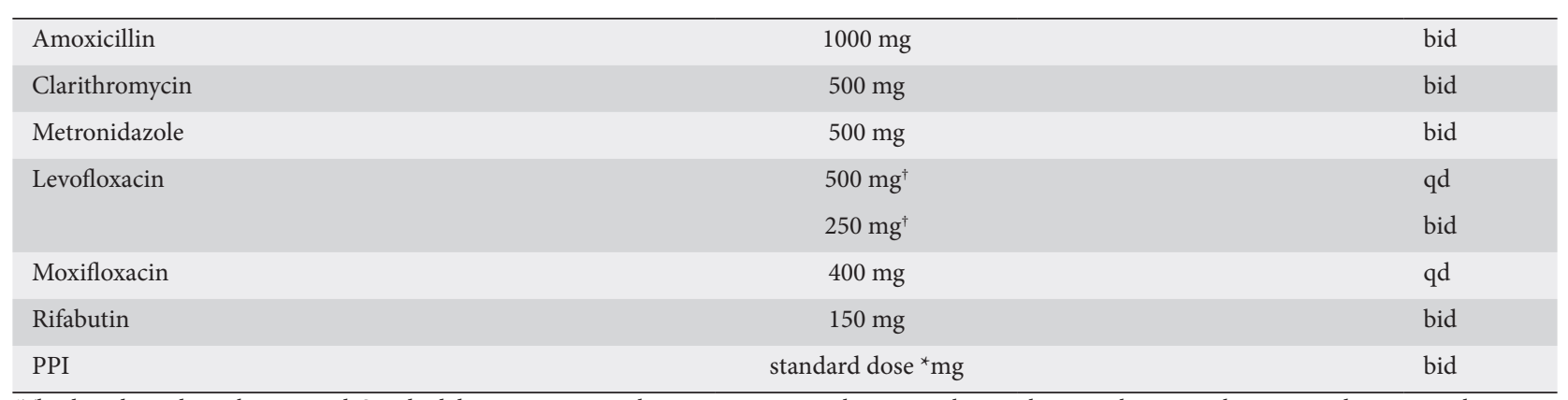

${ }^{\star}$ The dose depends on the PPI used. Standard doses are omeprazole $20 \mathrm{mg}$, esomeprazole $20 \mathrm{mg}$, rabeprazole $20 \mathrm{mg}$, lansoprazole $30 \mathrm{mg}$, and pantoprazole $40 \mathrm{mg}$ †In clinical trials, eradication appears to be similar in studies that use levofloxacin $250 \mathrm{mg}$ bid or $500 \mathrm{mg}$ qd dosing [4]

\section{References}

1. O’Morain NR, Dore PM, O'Connor AJP, Gisbert JP, O'Morain CA. Treatment of Helicobacter pylori infection in 2018. Helicobacter 2018;23(Suppl 1):e12519.

2. Graham DY, Fischbach L. Helicobacter pylori treatment in the era of increasing antibiotic resistance. Gut 2010;59:1143-1153.

3. Liatsos C, Leontiadis GI. The "report card" to grade H. pylori treatment regimens: is it achievable in real-world in areas with high clarithromycin resistance? J Gastrointestin Liver Dis 2017;26:203-204.

4. Gisbert JP, Morena F. Systematic review and meta-analysis: levofloxacin-based rescue regimens after Helicobacter pylori treatment failure. Aliment Pharmacol Ther 2006;23:35-44. 